\title{
1 Vitamin D Receptor Upregulates Tight Junction Protein Claudin-5 against
}

\section{Tumorigenesis}

3 Yongguo Zhang ${ }^{1}$, Shari Garrett ${ }^{1}$, Robert E. Carroll ${ }^{1}$, Yinglin Xia ${ }^{1}$, and Jun Sun ${ }^{2,3,4}$ *

4 1. Department of Medicine, College of Medicine, University of Illinois at Chicago,

5 Chicago, IL, USA

6 2. UIC Cancer Center, University of Illinois at Chicago, Chicago, IL, USA

7 3. Department of Microbiology/lmmunology, College of Medicine, University of Illinois at

8 Chicago, Chicago, IL, USA

9 4. Jesse Brown VA Medical Center Chicago, IL (537), USA

12 Correspondence:

13 Jun Sun, Ph.D., Professor, AGAF, FAPS

14 junsun7@uic.edu 
15 Author Contributions: YZ: acquisition, analysis, and interpretation of data, drafting of the

16 manuscript, and statistical analysis, SG: assistance with western blots and TJ data. YX:

17 Statistical analysis, microbiome data analysis, and manuscript drafting. REC: Provided

18 human biopsies and clinical perspectives of CRC. JS: study concept and design, analysis

19 and interpretation of data, writing of the manuscript for important intellectual content,

20 obtaining funding, and study supervision.

Funding: This research was funded by the UIC Cancer Center, the NIDDK/National the study design, data collection, analysis, and interpretation of data.

Acknowledgments: We would like to thank Dr. David Zhou for assisting with the CRC human samples, Drs. Shaoping Wu and Rong Lu for assisting with the AOM/DSS model, and Jason S. Xia for proofreading. The contents do not represent the views of the United States Department of Veterans Affairs or the United States Government.

Conflicts of Interest: The authors declare no conflict of interest. The funders played no 


\section{A short summary}

1. What is already known about this subject?

- Tight junction structures are essential for intestinal barrier integrity, inflammation, and

39 cancer.

- Vitamin $\mathrm{D}$ deficiency and the vitamin $\mathrm{D}$ receptor (VDR) play important roles in the

41 development of colon cancer.

\section{What are the new findings?}

43 - Our study is the first to link barrier function, a specific tight junction protein, and genetic susceptibility through intestinal epithelial VDR in human colorectal cancer.

- Our study fills an existing gap by characterizing the mechanism of intestinal epithelial

46 VDR in regulating barrier functions through alterations in TJs in tumorigenesis. VDR is important for the maintenance of the physiological level of the TJ protein Claudin-5 in the colon. The CLDN-5 gene is a downstream target of the VDR signaling pathway. Lack of VDR led to a reduction of Claudin-5 in tumors, whereas enhancing VDR increased Claudin-5 to protect the intestinal epithelial cells from tumorigenesis.

- We report fecal VDR reduction in a colon cancer model. This introduces the possibility

52 for the identification of new biomarkers and therapeutic targets to restore VDR-dependent 53 functions in CRC. 
58 Barrier function and VDR are not only essential for the maintenance of intestinal

59 homeostasis, but they are also critical for the development of chronic mucosal inflammation

60 and cancer. This knowledge can be immediately used to develop intestinal VDR and

61 Claudin-5 as clinical biomarkers for identifying patients who may benefit from currently

62 available interventions and could also be used for the eventual development of novel

63 strategies for the prevention and treatment of human CRC. 


\section{Abstract:}

Background/Objective: Tight junctions (TJs) are essential for barrier integrity, inflammation, and cancer. The TJ protein Claudin-5 in the epithelia forms paracellular barriers and pores for permeability. Vitamin $D$ and the vitamin $D$ receptor (VDR) play important roles in various cancers. Although VDR and Claudin-5 are all involved in colorectal cancer $(\mathrm{CRC})$, it remains unclear if they are closely related or function independently. Design: Using the human CRC database, we explored the correlation between VDR and Claudin-5. We then investigated the VDR regulation of Claudin-5 using VDR knockout $\left(\mathrm{VDR}^{-/-}\right)$and intestinal epithelial VDR knockout mice (VDR $\left.{ }^{\triangle I E C}\right)$ with chemical-induced colon cancer and an epithelial VDR overexpression model. Human samples, organoids, and intestinal epithelial cells were used to determine the underlying mechanisms. Results: In human colon cancer, colonic VDR expression was low and was significantly correlated with a reduction of Claudin- 5 mRNA and protein. In the colon of $\mathrm{VDR}^{-/-}$and $\mathrm{VDR}^{\triangle I E C}$ mice, deletion of $\mathrm{VDR}$ led to lower protein and mRNA levels of Claudin-5. Intestine permeability was increased in the AOM-DSS-induced VDR ${ }^{-/-}$colon cancer model. Lack of VDR and a reduction of Claudin-5 are associated with an increased number of tumors in the $\mathrm{VDR}^{-/-}$and $\mathrm{VDR}^{\triangle I E C}$ mice. Furthermore, gain and loss of function studies have identified $C L D N-5$ as a downstream target of the VDR signaling pathway. Epithelial VDR overexpression protected against the loss of Claudin 5 in response to intestinal inflammation Conclusion: This study advances the understanding of how VDR regulates intestinal barrier functions in tumorigenesis as a biomarker and potential treatment. 
bioRxiv preprint doi: https://doi.org/10.1101/2021.04.29.441977; this version posted April 30, 2021. The copyright holder for this preprint (which was not certified by peer review) is the author/funder. All rights reserved. No reuse allowed without permission.

88 Keywords: Claudin, barrier function, inflammation, colon cancer, colitis, tight junction,

89 Vitamin D, vitamin D receptor

90 


\section{$91 \quad$ Introduction}

92 Tight junction structures are essential for intestinal innate immunity and barrier function.

93 The disruption of TJs is a common manifestation of various diseases, including chronic

94 inflammation and cancer. Changes in the expression and distribution of TJ proteins such as

95 Claudin-2, -5 , and -8 lead to discontinuous TJs and barrier dysfunction in active Crohn's

96 disease (CD), a type of inflammatory bowel disease [1]. Claudin-5 is expressed in the

97 epithelia and endothelia and forms paracellular barriers and pores that determine

98 permeability. This protein is downregulated in colon cancer [2, 3].

99

100 VDR is a nuclear receptor that mediates most known functions of the biologically active

101 form of vitamin $D[4,5,6]$. VDR possesses multiple critical functions in regulating innate

102 and adaptive immunity, intestinal homeostasis, host response to microbiota, and tight

103 junction structure $[7,8,9,10,11,12,13,14]$. Vitamin D/VDR deficiency has been

104 implicated in patients with inflammatory bowel disease and colon cancer $[15,16,17,18,19$,

$10520,21]$. Our study demonstrated that VDR is essential for maintaining intestinal and

106 microbial homeostasis [22] and for protecting against intestinal tumorigenesis [23] [24].

107 Although vitamin D has been extensively studied, many critical questions regarding the

108 biological functions of intestinal VDR in CRC remain unanswered. Although VDR and TJ

109 proteins (e.g., Claudins) are involved in colon cancer, it remains unclear if they are closely

110 related or function independently. Considering the multiple functional roles of VDR in the

111 development of colon cancer [20,24], it is important to dissect the cellular and molecular 
112 mechanisms by which VDR contributes to barrier function in protecting the host from

113 tumorigenesis.

114

115 Here, we revisited the human CRC database and determined that colonic VDR expression

116 is low and positively correlated with the reduction of the TJ protein Claudin-5 in CRC,

117 including colitis-associated colon cancer. We investigated the novel role of VDR in

118 regulating Claudin-5 expression using VDR ${ }^{-/}$and intestinal epithelial VDR knockout mice

$119\left(\mathrm{VDR}^{\mathrm{\triangle IEC}}\right)$ in a colitis-associated colon cancer model. Human organoids, human colon

120 cancer samples, $\mathrm{VDR}^{-/-}$mouse embryonic fibroblasts (MEF) cells, and cultured intestinal

121 epithelial cells were used to determine the molecular mechanisms. We determined that

122 VDR is an important transcriptional regulator for the maintenance of physiological levels of

123 the target gene Claudin-5 in the intestine. Furthermore, we generated a conditional

124 intestinal epithelial VDR-overexpressed mouse model to study the protective role of VDR in

125 the maintenance of TJs in the context of inflammation. Our goal was to provide a detailed

126 understanding of how VDR status contributes to intestinal inflammation and cancer. Our

127 findings may offer an additional avenue to treat colon cancer by restoring barrier functions

128 and developing a new protocol for risk assessment and prevention of cancer. 


\section{Results}

132 Reduced VDR was positively correlated with low Claudin-5 expression in CRC

133 patients

134 We first examined the gene expression levels of VDR and Claudin-5 in normal and human

135 CRC samples by reviewing the GEO databases GSE 4183 and GSE 8671 from Affymetrix

136 data (human genome U133 Plus 2.0 arrays). Reduced VDR and Claudin-5 expression was

137 observed in patients with CRC (Fig. 1A). To quantify and visualize the correlations between

138 intestinal Claudin-5 and the VDR protein, we performed a regression analysis of VDR

139 against Claudin-5 and conducted a scatter plot with a regression line (Fig. 1B). We found

140 significantly coordinated expression of VDR and Claudin-5 in biopsy samples collected

141 from patients with CRC. We further analyzed data obtained from human colitis-associated

142 colon cancer (Fig. 1C). VDR and Claudin-5 expression was significantly reduced in patients

143 with colitis-associated CRC (GEO database GSE8671, GSE10714, and GSE37283) (Fig.

144 1C). We identified a positive correlation between VDR and Claudin-5 in biopsy samples

145 collected from colitis-associated CRC patients and healthy controls (Fig. 1D). We then

146 examined the protein levels of intestinal VDR in normal and CRC human colon samples

147 using IHC. Compared to normal intestines, CRC patients with CRC possessed significantly

148 lower VDR expression (Fig. 1E). Immunofluorescence (IF) staining of Claudin-5 revealed

149 significantly lower Claudin-5 expression in CRC human colon samples (Fig. 1F). We

150 performed correlation analysis and scatter plots of the staining intensity changes between

151 the VDR protein and Claudin-5 in the colon. The results revealed that the staining intensity

152 of Claudin-5 and intestinal VDR was positively associated with the Pearson correlation 
153 coefficient (Fig. 1G). Thus, we revealed that colonic VDR expression is low and is

154 correlated with the reduction of Claudin-5 at both mRNA and protein levels in human CRC,

155 including colitis-associated colon cancer.

\section{Larger and more tumors developed in VDR deficient mice}

158 Animal models have been developed to reflect the initiation and progression of human

159 colon cancer [25]. Azoxymethane (AOM) [26] mice develop hyperproliferative colonic

160 mucosa, aberrant crypt foci (ACF), and eventually carcinomas [27]. An AOM-dextran

161 sulfate sodium (DSS) model is widely used to study colitis-associated colon cancer [28].

162 We next investigated the role of VDR in regulating Claudin-5 expression in the development

163 of cancer using an AOM/DSS-treated mouse model (Fig. 2A). For wild-type $\mathrm{VDR}^{+/+}$and

164 whole-body VDR knockout (VDR $\left.{ }^{-/-}\right)$mice, representative colons with tumors are shown

165 (Fig. 2B). We observed that AOM/DSS-treated VDR ${ }^{-/}$mice developed more tumors in the colon (Fig. 2C). The maximum tumor size was significantly larger in $\mathrm{VDR}^{-/-}$mice compared

167 to that in $\mathrm{VDR}^{+/+}$mice (Fig. 2D). Furthermore, pathological analysis of colon samples

168 indicated differences in tumor stage (carcinoma versus adenoma) between $\mathrm{VDR}^{-/-}$mice and

169 the $\mathrm{VDR}^{+/+}$AOM/DSS experimental groups (Fig. 2E). Epithelial hyperproliferation plays a

170 critical role in the development of cancer. The IF data of the proliferative marker PCNA

171 revealed that PCNA in the colon was significantly increased in the $\mathrm{VDR}^{-/-}$mice compared to

172 that in the $\mathrm{VDR}^{+/+}$mice (Fig. 2F). Chronic inflammation is one of the factors that contribute

173 to CRC. We determined that the serum cytokines TNF- $\alpha$, IL-1 $\beta$, and IL-17 were significantly

174 higher in the $\mathrm{VDR}^{-/-}$mice, compared to levels in the $\mathrm{VDR}^{+/+}$mice (Fig. 2G). 


\section{VDR deletion leads to decreased Claudin-5 expression in tumor tissues}

177 We examined changes in barrier function by testing intestinal permeability in mice with or

178 without tumors. Mice were gavaged with fluorescein dextran (molecular weight $3 \mathrm{kDa}$ ). After

179 4-h, blood samples were collected for fluorescence intensity measurements. Higher

180 fluorescence intensity is indicative of higher intestinal permeability. As shown in Fig. 3A,

181 AOM/DSS treatment induced increased intestinal permeability in both $\mathrm{VDR}^{+/+}$and

$182 \mathrm{VDR}^{-/-}$mice, while the $\mathrm{VDR}^{-/-}$mice exhibited significantly higher permeability

183 post-treatment. Based on the in vivo intestinal permeability data, we hypothesized that the

184 TJ proteins would be altered in the AOM/DSS mice. In the VDR ${ }^{-/-}$mice, we observed

185 significant downregulation of Claudin-5 at the mRNA and protein levels in the colon (Fig.

186 3B \& 3C). Claudin-5 staining was observed at the crypt surface and at the lower portion of

187 the intestine. Reduced Claudin-5 expression was confirmed through the immunostaining of

188 AOM/DSS mice (Fig. 3D \&3G). However, VDR deletion did not alter the expression of the

189 TJ protein Claudin-7 in the colon of VDR ${ }^{-/-}$mice compared to that in VDR ${ }^{+/+}$mice (Fig. 3E).

190 VDR expression was also decreased in mice with AOM/DSS-induced colon cancer (Fig. 3F

191 and $\mathbf{3 H}$ ). Moreover, we used our recently established method to measure VDR levels

192 according to qPCR in fecal samples [29]. We detected a significant reduction in VDR in

193 fecal samples from mice with tumors (Fig. 3I). These data also suggest a decreased VDR

194 in epithelial cells that are shed from mice with tumors. 
198 Intestine permeability was also significantly increased in $V_{D R}^{\Delta I E C}$ mice with conditional

199 deletion of intestinal epithelial VDR (Fig. 4A). Intestinal epithelial VDR-specific deletion led

200 to significantly decreased Claudin-5 at the mRNA level in the colon (Fig. 4B) and further

201 decreased in the mice with colon cancer; however, other Claudin, such as Claudin-7, was

202 not altered in the absence of VDR. At the protein level, we found the reduced Claudin-5 in

203 the $V_{D R}^{\triangle I E C}$ mice (Fig. 4C). In tumor tissues of $V_{D R}^{\triangle I E C}$ mice epithelial Claudin-5 was

204 disorganized (Fig. 4D) and significantly decreased, compared to that in tumors of VDR ${ }^{\text {loxp }}$

205 mice (Fig. 4F). In contrast, Claudin-7 was not altered in tumors from VDR ${ }^{\triangle I E C}$ mice

206 compared to the tumor tissue of $V_{D R}^{\text {loxp }}$ mice (Fig. 4E). The VDR expression in fecal

207 samples was downregulated in the AOM-DSS VDR ${ }^{\text {loxp }}$ mice (Fig. 4G).

210 To confirm the direct regulation of VDR on Claudin-5, we examined various models at the

211 basal level without any treatment in vivo and in vitro. In the $\mathrm{VDR}^{-/-}$mice, we observed that

212 these mice possessed lower Claudin-5 protein levels in the colon than did VDR ${ }^{+/+}$mice, and

213 TJ Claudin-7 was not altered in the absence of VDR (Fig. S1A). We further detected

214 significantly decreased mRNA levels of Claudin-5 in the intestines of VDR ${ }^{-/-}$mice (Fig.

215 S1B). The density of Claudin-5 fluorescence staining was weaker in the $\mathrm{VDR}^{-1-}$ mouse

216 intestines (Fig. S1C). We also assessed the specificity of intestinal VDR in regulating

217 Claudin-5 expression in VDR ${ }^{\triangle I E C}$ mice (Fig. S1D). Claudin-5 mRNA levels were significantly 
218 reduced in $\mathrm{VDR}^{\triangle \mathrm{IEC}}$ mice compared to the levels in VDR-lox mice (Fig. S1E). As expected,

219 Claudin-7 expression remained unchanged. These data indicate that intestinal VDR

220 specifically regulates the expression level of Claudin-5 in the colon. To confirm our findings

221 in vitro, we used MEFs with VDR deletion. Lack of VDR led to a robust decrease in

222 Claudin-5 protein and mRNA levels in VDR ${ }^{-/-}$MEFs at the basal level (Fig. S1F and S1G).

223 The density of Claudin-5 fluorescence staining was also weaker in VDR ${ }^{-/-}$MEFs (Fig. S1H).

225 VDR acts as a transcription factor to regulate the expression of its target genes [30, 31].

226 Activated VDR binds to VDRE in the target gene promoter to regulate gene transcription

227 [32]. We reasoned that VDR may bind to the Claudin-5 promoter to thus alter the mRNA

228 expression of the Claudin-5 gene. Further, we performed a ChIP assay using the colon

229 mucosal extract from $\mathrm{VDR}^{-1-}$ mice and nonspecific $\lg G$ as a negative control to assess the

230 binding of VDR to the Claudin-5 promoter. The samples were amplified by conventional

231 PCR using Ik $\beta \alpha$ as a positive control and Claudin-1 as a negative control as indicated in

232 previous publications [33]. CHIP-PCR demonstrated that VDR bound to the Claudin-5

233 promoter in the $\mathrm{VDR}^{+/+}$mouse colon (Fig. 5A). The VDRE sequence

234 (AGTTCAAGTGGTTCT) within the Claudin-5 promoter region is shown in Figure 5B.

235 However, siRNA-based Claudin-5 knock-down did not reduce VDR expression at the

236 mRNA level (Fig. 5C). At the protein level, reduced Claudin-5 did not change the status of

237 VDR protein or Claudin-7 at the protein level (Fig. 5D). These results suggest that VDR

238 transcriptionally regulates Claudin-5 at the mRNA level and that VDR is the upstream

239 regulator of Claudin-5. 
241 High VDR levels led to increased Claudin-5 protein and mRNA levels in vitro.

242 We then explored the possibility of enhancing VDR to maintain the physiological level of

243 Claudin-5. Vitamin D3 is known to increase VDR expression and to activate VDR signaling.

244 We used the human colonic epithelial SKCO15 cell line that is widely used to study TJs [34,

245 35]. Claudin-5 mRNA level was significantly elevated in SKCO15 cells treated with vitamin

246 D3, while Claudin-7 mRNA was not altered by vitamin D3 treatment (Fig. 6A). The protein

247 level of Claudin-5 was induced by vitamin D3 (Fig. 6B). In vivo, Claudin-5 mRNA levels

248 were also increased in vitamin D3-treated mice (Fig. 6C). Colonoids are three-dimensional

249 (3D) cell cultures that incorporate a number of key features of the colon [36]. In this study,

250 we developed human colonoids (Fig. 6E), and we observed vitamin D3 treatment

251 significantly increased Claudin-5 mRNA levels in these colonoids (Fig. 6F). Furthermore,

252 vitamin D3 treatment significantly increased Claudin-5 protein levels in human colonoids,

253 whereas there was no change of Claudin-7 after vitamin D3 treatment (Fig. 6G).

Intestinal epithelial VDR overexpression protected against the loss of Claudin 5 in

respond to inflammation.

257 To further study the protective role of VDR in maintaining TJs in inflammation, we

258 generated a conditional intestinal epithelial VDR specific-overexpressed (O-VDR) mouse

259 model. Epithelial VDR overexpression in mouse intestines significantly increased Claudin-5

260 expression at both the mRNA and protein levels (Fig. 7A \& B). Claudin-5 exhibited a less

261 decreaseat the mRNA and protein and mRNA levels in the colon of O-VDR mice treated 
262 with DSS, compared to that in the O-VDR ${ }^{\operatorname{loxp}}$ mice (Fig. 7C \&7D). Using IF staining, we

263 determined that Claudin-5 was better preserved in the colon of O-VDR mice treated with

264 DSS compared to that in the O-VDR ${ }^{\operatorname{loxp}}$ mice (Fig. 7E \&7G). As anticipated, Claudin-7

265 expression was unchanged in the intestinal tissue of O-VDR mice that were treated with

266 DSS compared to that in the O-VDR ${ }^{\text {loxp }}$ mice (Fig. 7F). VDR levels in fecal samples were

267 detected using RT-PCR. VDR level was less decreased in DSS-treated O-VDR mice,

268 compared to that in O-VDR ${ }^{\text {loxp }}$ mice treated with DSS (Fig. 7H). Moreover, there were fewer

269 inflammatory cytokines such as IL-1 $\beta$ and IL-17 in the colons of DSS-induced O-VDR mice

270 compared to that in O-VDR ${ }^{\text {loxp }}$ mice (Fig. 7I). 


\section{Discussion}

In the current study, we determined that low colonic VDR expression was significantly

correlated with the reduction of Claudin-5 in human CRC, and we demonstrated that VDR is related to tumorigenesis.

The intestinal barrier includes several elements that aid in its function as a physical and

289 immunological barrier. These elements include the intestinal microbiota, secretory

290 immunoglobulin A, antimicrobial peptides, the inner lamina propria, and epithelial cells. At

291 the cellular level, epithelial cells play physical and physiological roles in health and disease.

292 VDR signaling is involved in the epithelial barrier function related to various human

293 diseases and remains largely unexplored [37]. As a nuclear receptor, VDR mediates most

294 known functions of 1,25-dihydroxyvitamin $\mathrm{D}\left(1,25(\mathrm{OH})_{2} \mathrm{D}_{3}\right)$, the active form of vitamin $\mathrm{D}$ [4].

295 However, the role of VDR has rarely been evaluated in studies examining human colon 
cancer. A recent study among patients with digestive tract cancer and vitamin D

297 supplementation determined that when compared to placebo, this treatment did not result in

298 significant improvement in relapse-free survival at 5 years [38]. The dosage of vitamin D3

299 was insufficient among participants who possessed more severe deficiencies at baseline.

300 Therefore, the status of the VDR level must to be considered over the course of many trials

301 or as a biological measurement to clarify the underlying mechanisms. The traditional model

302 of treatment using vitamin $\mathrm{D}$ that guided early vitamin studies should give way to a model

303 incorporating more complex mechanisms of action of the vitamin D/VDR system. The

304 intestinal barrier has been investigated by various methods, but correlation of results across

305 studies is difficult, representing a major shortcoming in the field [39].

307 The current study provides important insights into how VDR regulates Claudin-5 expression

308 under normal physiological conditions and during tumor growth in the colon. We revealed a

309 positive correlation between VDR and Claudin-5 at the mRNA and protein levels in healthy

310 and tumor colons, thus suggesting the unique role of Claudin-5 in the intestine. There are

31127 claudin family members that contribute to tight junctions [40], and not all claudins are the

312 same. Claudin-2- and Claudin-12 form paracellular $\mathrm{Ca}^{2+}$ channels in intestinal epithelia and

313 are important for vitamin D-dependent calcium homeostasis [41]. Our previous studies

314 have shown that Claudin-2 is hyperregulated in colitis with VDR reduction [42, 43]. Our

315 current study has demonstrated the mechanism on VDR-dependent function of Claudin-5 in

316 the intestine. Interestingly, we found that the tight junction Claudin-7 was not altered in

317 response to VDR-deficient status in the colon. In the lungs, VDR may play an important role 
318 in maintaining the pulmonary barrier integrity. We have reported that VDR deletion could

319 increase lung permeability by altering the expression of TJ molecules, particularly

320 Claudin-2, $-4,-10,-12$, and -18 [44]. Abnormal gut barrier function may serve as a

321 biomarker for the risk of IBD onset [45]. Our findings also suggest that the positively

322 correlated status of VDR and Claudin- 5 could be potentially applied to risk assessment,

323 early detection, and prevention of CRC, including colitis-associated colon cancer.

325 Colorectal cancer is the second-leading cause of cancer-related death and is most curable

326 in its early stages. Remarkable progress has been made in regard to colon cancer therapy,

327 including targeting barrier functions and microbiome [46]. The anti-TNF era has revealed

328 that mucosal healing is a key goal for therapy that predicts clinical remission and

329 resection-free survival in cancer patients. Many new targets (e.g., Jak inhibition, Toll-like

330 receptor 9 stimulation, and the addressin mucosal vascular addressin cell adhesion

331 molecule 1 emerge) have been recently tested for induction of mucosal healing and

332 protection and for induction and maintenance of remission in IBD. We aimed to provide a

333 detailed understanding of how VDR status contributes to changes in TJs in the context of

334 intestinal inflammation and colon cancer. Currently, there are no guidelines for monitoring

335 vitamin $D$ status, treating hypovitaminosis $D$, and maintaining optimal vitamin $D$ stores in

336 patients with IBD [47] or in CRC. These tasks may prove particularly difficult due to

337 malabsorption, gastrointestinal losses, and increased permeability that are associated with

338 intestinal dysfunction. Based on the research progress regarding the novel roles of VDR in

339 intestinal immunity and barrier functions, we expect that studies on VDR in intestinal 
bioRxiv preprint doi: https://doi.org/10.1101/2021.04.29.441977; this version posted April 30, 2021. The copyright holder for this preprint (which was not certified by peer review) is the author/funder. All rights reserved. No reuse allowed without permission.

340 barriers of colitis and colon cancer will have a marked impact on the prevention, diagnosis,

341 and therapy of colitis and colon cancer patients.

342 


\section{Human tissue samples}

345 This study was performed in accordance with approval from the University of Rochester

346 Ethics Committee (RSRB00037178) and UIC Ethics Committee (Institutional Review

347 Board: 2017-0384). Colorectal tissue samples were obtained from 10 CRC patients with

348 neoplasia and 10 patients without neoplasia patients (49-74years old). Human tissues for

349 organoids are from healthy volunteers.

\section{Gene expression datasets}

352 For expression analyses, we used microarray data reported in the NCBI Gene Expression

353 Omnibus database (GEO). To find the correlation between VDR and Claudin-5 at the gene 354 expression level, we gathered data by searching the Gene Expression Omnibus

355 (https://www.ncbi.nlm.nih.gov/geo/) for expression profiling studies using colonic samples

356 from colon cancer subjects. We randomly identified the GEO database reference series:

357 GSE4183 [48], GSE8671 [49], GSE10714 [50] and GSE37283) [51]. In these studies, the

358 authors performed microarray analysis using colonic biopsy samples from healthy controls

359 as well as from the inflamed and non-inflamed colonic mucosa from CRC subjects. From

360 the databases, 40 healthy controls and 62 CRC patients were randomly selected for CRC

361 group, while 16 healthy controls and 18 Colitis-associated CRC were randomly selected for

362 colitis-associated group. Both were subjected to further analyses. 


\section{Animals}

$366 \mathrm{VDR}^{-/-}$mice on a C57BL/6 background were obtained by breeding heterozygous $\mathrm{VDR}^{+/-}$

367 mice[43]. VDR ${ }^{\Delta I E C}$ mice were obtained by crossing the $V_{D R}^{\text {LoxP-B }}$ mice, originally provided 368 by Dr. Geert Carmeliet, with villin-cre mice (Jackson Laboratory, 004586), as we previously 369 reported [52].

371 Intestinal-specific VDR-overexpressing (O-VDR) mice were generated in C57BL/6 mice

372 strain background. The mouse VDR (mVDR) sequence was cloned into the Stbl3 vector 373 (size $6631 \mathrm{bp}$ ). The mVDR was cloned in (from $\sim 2210 \mathrm{bp}$ to $\sim 3316 \mathrm{bp}$ ) under EF1A 374 promoter (1bp to $1105 \mathrm{bp}$ ). A LoxP site was integrated after EF1A promoter (from $1105 \mathrm{bp}$ 375 to $2210 \mathrm{bp}$ ). VDR expression in O-VDR mice is Cre driven [53]. This O-VDR ${ }^{\text {loxp }}$ mouse line 376 is labeled as O-VDR ${ }^{\text {loxp }}$ in our gain of function study to distinct from the VDR ${ }^{\text {loxPlloxP }}$ mouse made for $\mathrm{VDR}^{\mathrm{\triangle IEC}}$ mice.

379 Experiments were performed on 2-3 months old mice including male and female. Mice 380 were provided with water ad libitum and maintained in a $12 \mathrm{~h}$ dark/light cycle. The animal 381 work was approved by the Rush University Animal Resources committee and UIC Office of 382 Animal Care. The animal work was approved by the UIC Office of Animal Care (ACC 383 15-231,17-218, and 18-216). 
Mice were treated with $10 \mathrm{mg} / \mathrm{kg}$ of AOM (Sigma-Aldrich, Milwaukee, WI, USA) by intraperitoneal injection as previously described [24]. After a 7-day recovery period, mice received three cycles of $2 \%$ DSS in the drinking water. Tumor counts and measurements were performed in a blinded fashion under a stereo-dissecting microscope (Nikon SMZ1000, Melville, NY, USA). Microscopic analysis was performed for severity of

391 inflammation and dysplasia on hematoxylin and eosin-stained 'Swiss rolled' colons by a gastrointestinal pathologist blinded to treatment conditions. Mice were scarified under anaesthesia.

\section{Induction of colitis and experimental design}

396 Eight- to ten-week-old mice of a specific genetic background were grouped randomly into

401 effect of DSS on both OVDR mice and compared them with their respective control group.

402 On day 7, mice were sacrificed, and intestinal tissue and blood samples were harvested for 403 RNA, protein, immunofluorescence, and cytokine analysis as described in the results 404 section. The samples were immediately frozen and kept at $-80^{\circ} \mathrm{C}$ until use. 
C57/BL/6 wild-type mice (6-8-week-old males and females) were gavaged with $1,25 D_{3}(0.2$ $\mu \mathrm{g} / \mathrm{day}$ in $100 \mu \mathrm{l}$ of corn oil) 3 times a week for 4 weeks, as described in our previous study

409 [54]. Intestinal tissue was collected following euthanasia.

\section{Cell culture}

412 Mouse embryonic fibroblasts (MEF) were isolated from embryonic day 13.5 embryos

413 generated from $\mathrm{VDR}^{+/-} \times \mathrm{VDR}^{+/-}$mouse breeding as previously described (32). $\mathrm{VDR}^{+/+}$and

$414 \mathrm{VDR}^{-/-}$MEFs were used in experiments after more than 15 passages when they had been

415 immortalized. MEFs and SKCO15 cells were grown in high glucose Dulbecco's Modified

416 Eagle Medium (DMEM) (Hyclone, SH30243.01) containing 10\% (v/v) fetal bovine serum 417 (GEMINI, 900-108), $50 \mu \mathrm{g} / \mathrm{ml}$ streptomycin, and $50 \mathrm{U} / \mathrm{ml}$ penicillin (Mediatech, Inc., $41830-002 \mathrm{Cl})$, as previously described [55].

\section{Colonoids cultures and treatment with Vit D3}

421 Human colonoids were prepared and maintained as previously described [56]. Mini gut 422 medium (advanced DMEM/F12 supplemented with HEPES, L-glutamine, N2, and B27) was 423 added to the culture, along with R-Spondin, Noggin, EGF, and Wnt-3a. At day 7 after 424 passage, colonoids were treated by Vit D3 $(20 \mathrm{nM})$ for indicated times.

\section{Western blot analysis and antibodies}

427 Mouse colonic epithelial cells were collected by scraping the tissue from the colon of the 428 mouse, including the proximal and distal regions [52]. The cells were sonicated in lysis 

X-100) with $0.2 \mathrm{mM}$ sodium ortho-vanadate, and protease inhibitor cocktail. The protein

431 concentration was measured using the BioRad Reagent (BioRad, Hercules, CA, USA).

432 Cultured cells were rinsed twice with ice-cold HBSS, lysed in protein loading buffer (50 mM

433 Tris, $\mathrm{pH}$ 6.8, $100 \mathrm{mM}$ dithiothreitol, 2\% SDS, 0.1\% bromophenol blue, $10 \%$ glycerol), and

434 then sonicated. Equal amounts of protein were separated by SDS-polyacrylamide gel 435 electrophoresis, transferred to nitrocellulose, and immunoblotted with primary antibodies.

436 The following antibodies were used: anti-Claudin-5 (Invitrogen, 35-2500, Carlsbad, CA, 437 USA), anti-Claudin-7 (Invitrogen, 34-9100, Carlsbad, CA, USA), anti-VDR (Santa Cruz 438 Biotechnology, SC-13133, Dallas, TX, USA), anti-Villin (Santa Cruz Biotechnology, 439 SC-7672 Dallas, TX, USA), or anti- $\beta$-actin (Sigma-Aldrich, A5316, St. Louis, MO, USA) 440 antibodies and were visualized by ECL (Thermo Fisher Scientific, 32106, Waltham, MA, 441 USA). Membranes that were probed with more than one antibody were stripped before 442 re-probing.

\section{Immunofluorescence}

445 Colonic tissues were freshly isolated and embedded in paraffin wax after fixation with $10 \%$ 446 neutral buffered formalin. Immunofluorescence was performed on paraffin-embedded 447 sections (4 $\mu \mathrm{m})$, after preparation of the slides as described previously [52], [55] followed by 448 incubation for 1 hour in blocking solution (2\% bovine serum albumin, $1 \%$ goat serum in 449 HBSS) to reduce nonspecific background. The tissue samples were incubated overnight 450 with primary antibodies at $4^{\circ} \mathrm{C}$. The following antibodies were used: anti-Claudin -5 and 
anti-Claudin-7. Slides were washed 3 times for 5 minutes each at room temperature in wash buffer. Samples were then incubated with secondary antibodies (goat anti-rabbit Alexa Fluor 488, Molecular Probes, CA; 1:200) for 1 hour at room temperature. Tissues were mounted with SlowFade Antifade Kit (Life technologies, s2828, Grand Island, NY, USA), followed by a coverslip, and the edges were sealed to prevent drying. Specimens were examined with a Zeiss laser scanning microscope LSM 710 (Carl Zeiss Inc.,

Oberkochen, Germany).

\section{Immunohistochemistry (IHC)}

460 After preparation of the slides, antigen retrieval was achieved by incubation of the slides for

$46115 \mathrm{~min}$ in the hot preheating sodium citrate $(\mathrm{pH} \mathrm{6.0)}$ buffer, and 30 min of cooling at room

462 temperature. Endogenous peroxidases were quenched by incubating the slides in $3 \%$ 463 hydrogen peroxide for $10 \mathrm{~min}$, followed by three rinses with HBSS, and incubation for 1 464 hour in $3 \%$ BSA $+1 \%$ goat serum in HBSS to reduce nonspecific background. Primary 465 antibodies VDR (1:300) was applied for overnight in a cold room. After three rinses the 466 slides with HBSS, they were incubated in secondary antibody $(1: 100$, Jackson 467 ImmunoResearch Laboratories, Cat.No.115-065-174, West Grove, PA, USA) for 1 hour at 468 room temperature. After washing with HBSS for 10 minutes, the slides were incubated with 469 vectastain ABC reagent (Vector Laboratories, Cat.No. PK-6100, Burlingame, CA 94010, 470 USA) for 1 hour. After washing with HBSS for five minutes, color development was 471 achieved by applying peroxidase substrate kit (Vector Laboratories, Cat.No. SK-4800, 472 Burlingame, CA 94010) for 2 to 5 minutes, depending on the primary antibody. The duration 
473 of peroxidase substrate incubation was determined through pilot experiments and was then

474 held constant for all of the slides. After washing in distilled water, the sections were

475 counterstained with haematoxylin (Leica, Cat.No.3801570, Wetzlar, Germany), dehydrated

476 through ethanol and xylene, and cover-slipped using a permount (Fisher Scientific,

477 Cat.No.SP15-100, Waltham, MA, USA ).

\section{Real Time quantitative PCR}

480 Total RNA was extracted from epithelial cell monolayers or mouse colonic epithelial cells

481 using TRIzol reagent (Fisher Scientific, 15596026, Waltham, MA, USA) [52]. RNA reverse 482 transcription was done using the iScript cDNA synthesis kit (Bio-Rad Laboratories, 483 1708891) according to the manufacturer's directions. The RT-cDNA reaction products were 484 subjected to quantitative real-time PCR using the CFX96 Real time PCR detection system 485 (Bio-Rad Laboratories, Hercules, CA, USA) and $\mathrm{iTaq}^{\mathrm{TM}}$ Universal SYBR green supermix 486 (Bio-Rad Laboratories, 1725121, Hercules, CA, USA) according to the manufacturer's 487 directions. All expression levels were normalized to $\beta$-actin levels of the same sample. 488 Percent expression was calculated as the ratio of the normalized value of each sample to 489 that of the corresponding untreated control cells. All real-time PCR reactions were 490 performed in triplicate. Primer sequences were designed using Primer-BLAST or were 491 obtained from Primer Bank primer pairs listed in Table 1. 
494 Binding of VDR to the Claudin-5 promoter was investigated using the ChIP assay as

495 described previously [57]. Briefly, mouse colonic epithelial cells were collected by scraping

496 the tissue from the colon of the mouse, cells were treated with $1 \%$ formaldehyde for 10 min

497 at $37^{\circ} \mathrm{C}$. Cells were washed twice in ice-cold phosphate buffered saline containing protease

498 inhibitor cocktail tablets. Cells were scraped into conical tubes, pelleted and lysed in SDS

499 Lysis Buffer. The lysate was sonicated to shear DNA into fragments of $200-1000$ bp (4

500 cycles of $10 \mathrm{~s}$ sonication, $10 \mathrm{~s}$ pausing, Branson Sonifier 250, USA). The chromatin

501 samples were pre-cleared with salmon sperm DNA-bovine serum albumin-sepharose

502 beads, then incubated overnight at $4{ }^{\circ} \mathrm{C}$ with VDR antibody. Immune complexes were

503 precipitated with salmon sperm DNA-bovine serum albumin-sepharose beads. DNA was

504 prepared by treatment with proteinase $\mathrm{K}$, extraction with phenol and chloroform, and 505 ethanol precipitation.

Multiplex ELISA assay

508 A mouse-specific ProcartalPlex ${ }^{\mathrm{TM}}$ Multiplex Immunoassay (26) plate from Invitrogen

509 Thermo Fisher Scientific was used to detect serum cytokine levels. The assay was 510 performed using the manufacturer's instruction manual using proper standards. Eventually,

511 the plate was read using a Megpix Luminex machine.

\section{Test fecal VDR by PCR}

514 Total RNA was extracted from mouse fecal samples, as previously described.[58] Briefly, 515 About $100 \mathrm{mg}$ of Frozen fecal pellet was used for RNA extraction by using Trizol Reagent 
516 (Thermo Fisher Scientific, Cat.No.15596018, Waltham, MA, USA). To increase RNA yield

517 in high quality, RNeasy minispin column (Qiagen, Cat No.217004, Hilden, Germany) was

518 used by following the manufacturer's instructions.

\section{Statistical Analysis}

521 All data are expressed as the mean \pm SD. All statistical tests were 2 -sided. All $p$ values $<$

5220.05 were considered statistically significant. After the Shapiro-Wilk test confirmed that the

523 data are normally distributed, the differences between samples were analyzed using

524 unpaired $t$ test for two groups and using one-way ANOVA for more than two groups as

525 appropriate, respectively. The $p$ values in ANOVA analysis and generalized linear mixed

526 models were adjusted using the Tukey method to ensure accurate results. Pairwise

527 correlation analyses and scatter plots were conducted staining intensity changes between

528 VDR protein and Claudin-5, using SAS version 9.4 (SAS Institute, Inc., Cary, NC, USA).

529 Other statistical analyses were performed using GraphPad Prism 6 (GraphPad, Inc., San

530 Diego, CA., USA). 


\section{Tables}

Table 1: Real-time PCR Primers

\begin{tabular}{|c|c|}
\hline Primers name & Sequence \\
\hline $\mathrm{m} \beta$-actinF & 5'-TGTTACCAACTGGGACGACA-3' \\
\hline$m \beta$-actinR & 5'-CTGGGTCATCTTTTCACGGT-3' \\
\hline mVDRF & 5'-GAATGTGCCTCGGATCTGTGG-3' \\
\hline mVDRR & 5'-ATGCGGCAATCTCCATTGAAG-3' \\
\hline mClaudin-5F & 5'- AGGCACGGGTAGCACTCACG-3' \\
\hline mClaudin-5R & 5' - CATAGTTCTTCTTGTCGTAATC-3' \\
\hline mClaudin-7F & 5'-GCGACAACATCATCACAGCC-3' \\
\hline mClaudin-7R & 5'-CCTTGGAGGAATTGGACTTGG-3' \\
\hline mTNF- $\alpha \mathrm{F}$ & 5'-СССТСАСАСТСАGАТСАТСТTСТ-3' \\
\hline mTNF- $\alpha$ R & 5'-GCTACGACGTGGGCTACAG-3' \\
\hline $\mathrm{mIL}-1 \beta \mathrm{F}$ & 5'-GCAACTGTTCCTGAACTCAACT-3' \\
\hline $\mathrm{mIL}-1 \beta R$ & 5'-ATCTTTTGGGGTCCGTCAACT-3' \\
\hline mIL-17F & 5'-TTTAACTCCCTTGGCGCAAAA-3' \\
\hline mIL-17R & 5'-CTTTCCCTCCGCATTGACAC-3' \\
\hline$h \beta$-actinF & 5'-AGAGCAAGAGAGGCATCCTC-3' \\
\hline$h \beta$-actinR & 5'-CTCAAACATGATCTGGGTCA-3' \\
\hline hVDRF & 5'-GGACTGCCGCATCACCAA-3' \\
\hline hVDRR & 5'-TCATCTCCCGCTTCCTCT-3' \\
\hline hClaudin-5F & 5'-TTCGCCAACATTGTCGTCC-3' \\
\hline hClaudin-5R & 5'-TCTTCTTGTCGTAGTCGCCG-3' \\
\hline hClaudin-7F & 5'-CATCGTGGCAGGTCTTGCC-3' \\
\hline hClaudin-7R & 5'-GATGGCAGGGCCAAACTCATAC-3' \\
\hline
\end{tabular}


Fig. 1 Reduced VDR was correlated with low Claudin-5 expression in human CRC

(A) Reduced VDR and Claudin-5 expression in patients with CRC (GEO database

550 Colitis-associated CRC patients. We performed a regression of VDR against Claudin-5 and

551 conducted a scatter plot analysis with a regression line (GEO database GSE8671,

552 GSE10714 and GSE37283 Normal, n=16; Colitis-associated CRC, $n=18$; the correlation is

5530.2549 with $p$-value $=0.1457)$. (E) Intestinal VDR staining in normal and CRC human colon

554 samples. Compared to normal intestines, intestines from CRC patients possessed

555 significantly lower VDR expression. (Images are representative of experiments performed

556 in triplicate; Normal, $\mathrm{n}=10$; Colorectal cancer, $\mathrm{n}=10$; Student $t$ test; $\left.{ }^{*} P<0.05\right)$. (F) IF

557 staining of Claudin-5 in normal and CRC human colon samples. Compared to normal 
558 intestines, the intestines of CRC patients exhibited significantly lower Claudin-5 expression.

559 (Images are representative of experiments in triplicate; Normal, $n=10 ;$ Colon cancer, $n=10$;

560 Student $t$ test; $\left.{ }^{*} P<0.05\right)$. (G) The correlation analysis of staining intensity between

561 intestinal Claudin-5 and VDR in human colon samples. $(P<0.0734, n=6$ for Normal and

562 Colon cancer, respectively).

564 Fig. 2 VDR $^{-/-}$mice developed a greater number of tumors compared to tumors in $565 \mathrm{VDR}^{+/+}$mice.

566 (A) Schematic overview of the AOM/DSS-induced colon cancer model. AOM $(10 \mathrm{mg} / \mathrm{kg})$

567 was injected on day 0 . At Day $7,2 \%$ DSS solution was administered to mice in drinking

568 water. Seven days of DSS was followed by three weeks of drinking water that was free of

569 DSS. An additional two cycles of DSS were administered prior to scarification at Week 19.

570 (B) Colonic tumors in situ. Representative colons from different groups. Tumors are

571 indicated by red arrows. (C) Tumor numbers in AOM-DSS-induced colon cancer model:

$572 \mathrm{VDR}^{++}$and $\mathrm{VDR}^{-/-}$mice (data are expressed as mean \pm SD. $\mathrm{n}=10-13$, one-way ANOVA

573 test, $\left.{ }^{*} \mathrm{P}<0.05\right)$. (D) Max tumor size in AOM-DSS induced colon cancer model: $\mathrm{VDR}^{+/+}$and

$574 \mathrm{VDR}^{-1-}$ mice (data are expressed as mean $\pm \mathrm{SD} . \mathrm{n}=10-13$, one-way ANOVA test,

575 *P < 0.05). (E) Representative H\&E staining of "Swiss rolls" of representative colons from

576 the indicated groups. Images are from a single experiment and are representative of 10

577 mice per group. (F) Quantitation of PCNA-positive cells in control mucosa per intestinal

578 glands or in the tumors tissue per high-power field. PCNA expression in the tumor tissue of

$579 \mathrm{VDR}^{-/-}$mice was significantly higher, compared to that in the $\mathrm{VDR}^{+/+}$mice (data are 
expressed as mean \pm SD. $n=5$, student's t-test, $\left.{ }^{*} P<0.05\right)$. (G) Serum cytokines such as

TNF- $\alpha$, IL-1 $\beta$, and IL-17 were significantly increased, particularly in the AOM-DSS-induced $\mathrm{VDR}^{-/-}$mice colon cancer model. Each single experiment was assayed in triplicate. Data are expressed as mean $\pm S D$. $n=6$, one-way ANOVA test, ${ }^{*} P<0.05$.

(A) Intestine permeability increased in the AOM-DSS-induced $\mathrm{VDR}^{-{ }^{--}}$mice colon cancer

\pm SD. $n=5$, one-way ANOVA test, ${ }^{*} P<0.05$ ). (D) (G) Claudin-5 was decreased in the

594 tumor tissue of $\mathrm{VDR}^{-/-}$mice, compared to levels in the tumor tissue of $\mathrm{VDR}^{+/+}$mice

595 according to immunofluorescence staining. Images are from a single experiment and are

596 representative of 6 mice per group. (Data are expressed as mean $\pm S D$. $n=6$, one-way

597 ANOVA test, * $P<0.05$ ). (E) Claudin-7 was unchanged in the tumor tissue of $V^{-1 /-}$ mice

598 compared to levels in the tumor tissue of $\mathrm{VDR}^{+/+}$mice according to immunofluorescence

599 staining. Images are from a single experiment and are representative of 6 mice per group.

$600(\mathbf{F})(\mathbf{H})$ Intestinal VDR expression was decreased in the AOM-DSS-induced colon cancer 601 model. Images are from a single experiment and are representative of 6 mice per group. 
602 Data are expressed as mean $\pm S D . n=6$, one-way ANOVA test, ${ }^{*} P<0.05$ ). (I) VDR levels

603 in fecal samples were detected using RT-PCR. VDR expression was downregulated in the

604 AOM-DSS-treated $\mathrm{VDR}^{+/+}$mice (data are expressed as mean $\pm \mathrm{SD} . n=5$, one-way

605 ANOVA test, $\left.{ }^{*} \mathrm{P}<0.05\right)$.

606

607 Fig. 4 VDR-specific deletion in mouse intestines lead to decreased Claudin-5

\section{expression in tumor tissues}

609 (A) Intestine permeability was increased in the AOM-DSS-induced VDR ${ }^{\triangle I E C}$ mice colon

610 cancer model (data are expressed as mean \pm SD; $n=5$ mice/group, 1 -way ANOVA test;

$\left.611{ }^{*} P<0.05\right)$. (B) VDR-specific deletion in mouse intestines decreased Claudin-5 at the

612 mRNA level in the colon (data are expressed as mean \pm SD. $n=5$, one-way ANOVA test,

$\left.613{ }^{*} \mathrm{P}<0.05\right)$. (C) VDR-specific deletion in mouse intestines decreased Claudin-5 protein in

614 the colon (data are expressed as mean $\pm S D . n=5$, one-way ANOVA test, ${ }^{*} P<0.05$ ).

615 Claudin-5 was decreased in the tumor tissue of $\mathrm{VDR}^{\triangle \mathrm{IEC}}$ mice compared to levels in the tumor tissue of $\mathrm{VDR}^{\text {loxp }}$ mice according to immunofluorescence staining. Images are from a

617 single experiment and are representative of 6 mice per group. (E) Claudin-7 expression

618 was not changed in the AOM-DSS-induced VDR ${ }^{\text {loxp }}$ mice colon cancer model. Images are

619 from a single experiment and are representative of 6 mice per group. (F) Intensity of the

620 staining of Claudin-5. (Data are expressed as mean \pm SD. $n=6$, one-way ANOVA test,

$\left.621{ }^{*} \mathrm{P}<0.05\right)$. (G) VDR level in fecal samples was detected by RT-PCR. VDR expression was

622 downregulated in the AOM-DSS-treated VDR ${ }^{\text {loxp }}$ mice (data are expressed as

623 mean \pm SD. $n=3$, one-way ANOVA test, $\left.{ }^{*} \mathrm{P}<0.05\right)$. 
626 (A) CHIP-PCR amplification demonstrated that VDR binds to the promoter regions of

627 Claudin-5 in mouse colons. PCR assays were performed and included input-positive

628 controls and IgG/villin-negative controls. $n=3$ separate experiments. (B) Claudin-5

629 promoter regions with VDRE sequence. (C) Claudin-5 knockdown using siRNA (40 nM for

63072 hours) did not reduce VDR expression at the mRNA level. (Data are expressed as

631 mean \pm SD. $n=3$, one-way ANOVA test, $\left.{ }^{*} P<0.05\right)$. (D) The protein expression in

632 SKCO15 cells using siRNA (40 nM for 72 hours). (data are expressed as mean \pm SD. $n=3$,

633 one-way ANOVA test, $\left.{ }^{*} \mathrm{P}<0.05\right)$.

635 Fig. 6. High VDR levels led to increased Claudin-5 at the protein and mRNA levels in 636 vitro.

637 (A) Claudin-5 mRNA and (B) protein levels were increased after 24-hour vitamin

638 D3 treatment at $20 \mathrm{nM}$ in SKCO15 cells (data are expressed as mean \pm SD. student's t-test,

$639{ }^{*} \mathrm{P}<0.05 . \mathrm{n}=3$ ). (C) Claudin-5 mRNA and (D) protein levels were higher in vitamin 640 D3-treated $V_{D R}^{+/+}$mice. VDR ${ }^{+/+}$mice (6-8 weeks) were gavaged by $0.2 \mu$ v vitamin $\mathrm{D} 3$ in $6410.1 \mathrm{ml}$ corn oil for 3 times per week for 4 weeks (data are expressed as mean \pm SD.

642 student's t-test, ${ }^{*} \mathrm{P}<0.05 . \mathrm{n}=5$ mice / group). (E) The micrographs show representative 643 human colonoids that were treated with Vit $D_{3}(20 \mathrm{nM})$ for the indicated time points. (F)

644 Claudin-5 mRNA and (G) protein levels were increased after vitamin D3 treatment in 
645

646 Images are from a single experiment and are representative of 5 mice per group.

661 Intensity of the staining of Claudin-5. Images are from a single experiment and are 662 representative of 5 mice per group. (Data are expressed as mean $\pm S D$. $n=5$, one-way 663 ANOVA test, $\left.{ }^{*} \mathrm{P}<0.05\right)$. (H) VDR level in fecal samples was detected by RT-PCR. VDR 664 expression was less decreased in O-VDR mice treated with DSS compared to levels in the

\section{Fig. 7. Overexpressed intestinal epithelial VDR led to increased Claudin-5 and} reduced inflammation in vivo.

(A) VDR overexpression in mice intestines increased Claudin-5 expression in the colon at the mRNA and $(B)$ protein levels (data are expressed as mean $\pm S D$. $n=3$, one-way ANOVA test, $\left.{ }^{*} \mathrm{P}<0.05\right)$. (C) Claudin-5 was less decreased at the mRNA and (D) protein levels in the intestinal tissue of O-VDR mice treatment with DSS compared to levels in the O-VDR ${ }^{\text {loxp }}$ mice (data are expressed as mean $\pm S D . n=3$, one-way ANOVA test, $\left.{ }^{*} P<0.05\right)$. (E) Claudin-5 was less decreased in the intestinal tissue of O-VDR mice treated with DSS compared to levels in the O-VDR ${ }^{\text {loxp }}$ mice, according to immunofluorescence staining. Images are from a single experiment and are representative of 5 mice per group.

(F) Claudin-7 was unchanged in the intestinal tissue of O-VDR mice treated with DSS compared to levels in the $\mathrm{O}-\mathrm{VDR}^{\mathrm{loxp}}$ mice according to immunofluorescence staining. O-VDR ${ }^{\text {loxp }}$ mice treated with DSS (data are expressed as mean \pm SD. $n=3$, one-way ANOVA test, ${ }^{*} \mathrm{P}<0.05$ ). (I) The inflammatory cytokines $\mathrm{IL}-1 \beta$ and $\mathrm{IL}-17$ were less 
bioRxiv preprint doi: https://doi.org/10.1101/2021.04.29.441977; this version posted April 30, 2021. The copyright holder for this preprint (which was not certified by peer review) is the author/funder. All rights reserved. No reuse allowed without permission.

667 increased in the DSS-induced O-VDR mice colitis model compare to levels in O-VDR ${ }^{\operatorname{loxp}}$

668 mice (data are expressed as mean \pm SD. $n=3$, one-way ANOVA test, ${ }^{*} P<0.05$ ).

669 
670 Fig. S1. VDR deficiency in intestinal epithelial cells of mice leads to the reduction of

671 Claudin-5 at both the mRNA and protein levels in vivo.

672 (A) Claudin-5 protein and (B) mRNA levels were significantly lower in VDR ${ }^{-/}$mice compared

673 to levels in the $\mathrm{VDR}^{+/+}$mice (data are expressed as mean $\pm \mathrm{SD}$. $\mathrm{n}=5$, student's t-test,

$\left.674{ }^{*} \mathrm{P}<0.05\right)$ (C) Location of Claudin-5 protein in the colons of $\mathrm{VDR}^{+/+}$and $\mathrm{VDR}^{-/-}$mice.

675 Images are from a single experiment and are representative of 5 mice per group. (D)

676 Claudin-5 protein and (E) mRNA levels were significantly lower in VDR ${ }^{\triangle I E C}$ mice compared

677 to levels in the VDR ${ }^{\text {loxp }}$ mice (data are expressed as mean $\pm S D . n=5$, student's t-test,

$\left.678{ }^{*} \mathrm{P}<0.05\right)$. (F) Claudin-5 protein and $(\mathbf{G})$ mRNA were both decreased in VDR ${ }^{-/-}$MEF cells

679 (data are expressed as mean \pm SD. $n=3$, student's t-test, $\left.{ }^{*} P<0.05\right)$. (H) Location and 680 quantification of Claudin-5 protein in $\mathrm{VDR}^{+/+}$and $\mathrm{VDR}^{-/-} \mathrm{MEF}$ cells. Images are from a single 681 experiment performed in triplicate. (Data are expressed as mean $\pm S D$. $n=3$, one-way 682 ANOVA test, $\left.{ }^{*} \mathrm{P}<0.05\right)$. 


\section{References}

1 Zeissig S, Burgel N, Gunzel D, Richter J, Mankertz J, Wahnschaffe U, et al. Changes in expression and distribution of claudin 2, 5 and 8 lead to discontinuous tight junctions and barrier dysfunction in active Crohn's disease. Gut 2007;56:61-72.

2 Zhu L, Han J, Li L, Wang Y, Li Y, Zhang S. Claudin Family Participates in the Pathogenesis of Inflammatory Bowel Diseases and Colitis-Associated Colorectal Cancer. Frontiers in immunology 2019;10:1441.

3 Cherradi S, Martineau P, Gongora C, Del Rio M. Claudin gene expression profiles and clinical value in colorectal tumors classified according to their molecular subtype. Cancer management and research 2019;11:1337-48.

4 Haussler MR, Whitfield GK, Haussler CA, Hsieh J-C, Thompson PD, Selznick SH, et al. The nuclear vitamin $\mathrm{D}$ receptor: biological and molecular regulatory properties revealed. J Bone and Mineral Research 1998;13:325-49.

5 Xue Y, Fleet JC. Intestinal vitamin D receptor is required for normal calcium and bone metabolism in mice. Gastroenterology 2009;136:1317-27, e1-2.

6 Bouillon R, Carmeliet G, Verlinden L, van Etten E, Verstuyf A, Luderer HF, et al. Vitamin $D$ and human health: lessons from vitamin $D$ receptor null mice. Endocr Rev 2008;29:726-76.

7 Ogura M, Nishida S, Ishizawa M, Sakurai K, Shimizu M, Matsuo S, et al. Vitamin D3 modulates the expression of bile acid regulatory genes and represses inflammation in bile duct-ligated mice. J Pharmacol Exp Ther 2009;328:564-70.

8 Kamen DL, Tangpricha V. Vitamin D and molecular actions on the immune system: modulation of innate and autoimmunity. J Mol Med;88:441-50.

9 Waterhouse JC, Perez TH, Albert PJ. Reversing bacteria-induced vitamin D receptor dysfunction is key to autoimmune disease. Ann N Y Acad Sci 2009;1173:757-65.

10 Liu PT, Krutzik SR, Modlin RL. Therapeutic implications of the TLR and VDR partnership. Trends Mol Med 2007;13:117-24.

11 Gombart AF, Borregaard N, Koeffler HP. Human cathelicidin antimicrobial peptide (CAMP) gene is a direct target of the vitamin $D$ receptor and is strongly up-regulated in myeloid cells by 1,25-dihydroxyvitamin D3. FASEB J 2005;19:1067-77.

12 Kong J, Zhang Z, Musch MW, Ning G, Sun J, Hart J, et al. Novel role of the vitamin $\mathrm{D}$ receptor in maintaining the integrity of the intestinal mucosal barrier. Am J Physiol Gastrointest Liver Physiol 2008;294:G208-16.

13 Adams JS, Hewison M. Unexpected actions of vitamin D: new perspectives on the regulation of innate and adaptive immunity. Nat Clin Pract Endocrinol Metab 2008;4:80-90.

14 Yu S, Bruce D, Froicu M, Weaver V, Cantorna MT. Failure of T cell homing, reduced CD4/CD8alphaalpha intraepithelial lymphocytes, and inflammation in the gut of vitamin D receptor KO mice. Proceedings of the National Academy of Sciences of the United States of America 2008;105:20834-9.

15 Lloyd-Price J, Arze C, Ananthakrishnan AN, Schirmer M, Avila-Pacheco J, Poon TW, et al. Multi-omics of the gut microbial ecosystem in inflammatory bowel diseases. Nature 2019;569:655-62. 
16 Abreu MT, Kantorovich V, Vasiliauskas EA, Gruntmanis U, Matuk R, Daigle K, et al. Measurement of vitamin $D$ levels in inflammatory bowel disease patients reveals a subset of Crohn's disease patients with elevated 1,25-dihydroxyvitamin $D$ and low bone mineral density. Gut 2004;53:1129-36.

17 Lim WC, Hanauer SB, Li YC. Mechanisms of disease: vitamin D and inflammatory bowel disease. Nat Clin Pract Gastroenterol Hepatol 2005;2:308-15.

18 Wang TT, Dabbas B, Laperriere D, Bitton AJ, Soualhine H, Tavera-Mendoza LE, et al. Direct and indirect induction by 1,25-dihydroxyvitamin D3 of the NOD2/CARD15-defensin beta2 innate immune pathway defective in Crohn disease. The Journal of biological chemistry;285:2227-31.

19 Rufo PA, Bousvaros A. Current therapy of inflammatory bowel disease in children. Paediatr Drugs 2006;8:279-302.

20 Sun J. Vitamin D and mucosal immune function. Curr Opin Gastroenterol

$740 \quad 2010 ; 26: 591-5$.

74121 Song M, Chan AT, Jun J. Features of the Gut Microbiome, Diet, and Environment That Influence Risk of Colorectal Cancer. Gastroenterology 2020.

74322 Lu R, Zhang Y, Xia Y, Zhang J, Kaser A, Blumberg R, et al. Paneth cell alertness to pathogens maintained by vitamin D receptors. Gastroenterology 2020.

23 Zhang Y-G, Lu R, Wu S, Chatterjee I, Zhou D, Xia Y, et al. Vitamin D receptor protects against dysbiosis and tumorigenesis via the JAK/STAT pathway in intestine. Biorxiv 2020;02.

74824 Zhang YG, Lu R, Wu S, Chatterjee I, Zhou D, Xia Y, et al. Vitamin D Receptor 749 Protects Against Dysbiosis and Tumorigenesis via the JAK/STAT Pathway in Intestine. Cell 750 Mol Gastroenterol Hepatol 2020;10:729-46.

75125 Wong SH, Zhao L, Zhang X, Nakatsu G, Han J, Xu W, et al. Gavage of Fecal

752 Samples From Patients With Colorectal Cancer Promotes Intestinal Carcinogenesis in 753 Germ-Free and Conventional Mice. Gastroenterology 2017;153:1621-33 e6.

75426 Andoh A, Imaeda H, Aomatsu T, Inatomi O, Bamba S, Sasaki M, et al. Comparison of the fecal microbiota profiles between ulcerative colitis and Crohn's disease using

756 terminal restriction fragment length polymorphism analysis. J Gastroenterol

$757 \quad 2011 ; 46: 479-86$.

$758 \quad 27$ Bird RP, Good CK. The significance of aberrant crypt foci in understanding the 759 pathogenesis of colon cancer. Toxicol Lett 2000;112-113:395-402.

76028 Kang X, Zhang R, Kwong TN, Lui RN, Wu WK, Sung JJ, et al. Serrated neoplasia 761 in the colorectum: gut microbiota and molecular pathways. Gut Microbes 2021;13:1-12.

76229 Yongguo Zhang YX, Jun Sun. . A simple and sensitive method to detect vitamin D 763 receptor expression in various disease models using stool samples. Genes and Diseases 7642020.

76530 Wu S, Zhang YG, Lu R, Xia Y, Zhou D, Petrof EO, et al. Intestinal epithelial vitamin 766 D receptor deletion leads to defective autophagy in colitis. Gut 2015;64:1082-94.

76731 Sun J, Kong J, Duan Y, Szeto FL, Liao A, Madara JL, et al. Increased NF-kappaB 768 activity in fibroblasts lacking the vitamin D receptor. Am J Physiol Endocrinol Metab

769 2006;291:E315-22. 
32 Kato S. The function of vitamin D receptor in vitamin D action. J Biochem 2000;127:717-22.

77233 Zhang Y-g, Wu S, Lu R, Zhou D, Zhou J, Carmeliet G, et al. Tight junction CLDN2 gene is a direct target of the vitamin D receptor. Scientific Reports 2015;5:10642.

34 Capaldo CT, Koch S, Kwon M, Laur O, Parkos CA, Nusrat A. Tight function zonula occludens-3 regulates cyclin D1-dependent cell proliferation. Molecular biology of the cell 2011;22:1677-85.

35 Ivanov AI, McCall IC, Babbin B, Samarin SN, Nusrat A, Parkos CA. Microtubules regulate disassembly of epithelial apical junctions. BMC cell biology 2006;7:12. HMGB1 inhibits bacterial infection via STAT3 regulation of autophagy. Autophagy 2019;15:1935-53.

37 Zhang YG, Wu S, Sun J. Vitamin D, Vitamin D Receptor, and Tissue Barriers. Tissue barriers 2013;1.

38 Urashima M, Ohdaira H, Akutsu T, Okada S, Yoshida M, Kitajima M, et al. Effect of Cancers: The AMATERASU Randomized Clinical Trial. JAMA 2019;321:1361-9.

39 Vancamelbeke $\mathrm{M}$, Vermeire $\mathrm{S}$. The intestinal barrier: a fundamental role in health and disease. Expert Rev Gastroenterol Hepatol 2017;11:821-34.

40 Mineta K, Yamamoto Y, Yamazaki Y, Tanaka H, Tada Y, Saito K, et al. Predicted expansion of the claudin multigene family. FEBS Letters 2011;585:606-12. junction proteins claudin-2 and -12 are critical for vitamin D-dependent Ca2+ absorption between enterocytes. Molecular biology of the cell 2008;19:1912-21. Receptor Leads to Hyperfunction of Claudin-2 in Intestinal Inflammatory Responses. Inflamm Bowel Dis 2019;25:97-110.

43 Zhang YG, Wu S, Lu R, Zhou D, Zhou J, Carmeliet G, et al. Tight junction CLDN2 gene is a direct target of the vitamin D receptor. Sci Rep 2015;5:10642. Destruction of Tight and Adherens Junctions in Lungs. Tissue barriers 2018;6:1-13.

80145 Turpin W, Lee SH, Raygoza Garay JA, Madsen KL, Meddings JB, Bedrani L, et al. 802 Increased Intestinal Permeability is Associated with Later Development of Crohn's Disease. 803 Gastroenterology 2020.

$804 \quad 46 \quad$ Wong SH, Yu J. Gut microbiota in colorectal cancer: mechanisms of action and clinical applications. Nat Rev Gastroenterol Hepatol 2019;16:690-704.

80647 Pappa HM, Grand RJ, Gordon CM. Report on the vitamin D status of adult and pediatric patients with inflammatory bowel disease and its significance for bone health and

808 disease. Inflamm Bowel Dis 2006;12:1162-74.

80948 Galamb O, Gyorffy B, Sipos F, Spisak S, Nemeth AM, Miheller P, et al.

810 Inflammation, adenoma and cancer: objective classification of colon biopsy specimens with 811 gene expression signature. Disease markers 2008;25:1-16. 

$\mathrm{H}$, et al. Transcriptome profile of human colorectal adenomas. Molecular cancer research :

814 MCR 2007;5:1263-75.

81550 Galamb O, Sipos F, Solymosi N, Spisak S, Krenacs T, Toth K, et al. Diagnostic 816 mRNA expression patterns of inflamed, benign, and malignant colorectal biopsy specimen 817 and their correlation with peripheral blood results. Cancer epidemiology, biomarkers \& 818 prevention : a publication of the American Association for Cancer Research, cosponsored 819 by the American Society of Preventive Oncology 2008;17:2835-45.

82051 Pekow J, Dougherty U, Huang Y, Gometz E, Nathanson J, Cohen G, et al. Gene 821 signature distinguishes patients with chronic ulcerative colitis harboring remote neoplastic 822 lesions. Inflamm Bowel Dis 2013;19:461-70.

82352 Zhang H, Wu H, Liu L, Li H, Shih DQ, Zhang X. 1,25-dihydroxyvitamin D3 824 regulates the development of chronic colitis by modulating both T helper (Th)1 and Th17 825 activation. APMIS 2015;123:490-501.

$82653 \quad$ Chatterjee I, Zhang Y, Zhang J, Lu R, Xia Y, Sun J. Overexpression of Vitamin D 827 Receptor in Intestinal Epithelia Protects Against Colitis via Upregulating Tight Junction 828 Protein Claudin 15. Journal of Crohn's and Colitis 05 March, 2021.

82954 Lu R, Zhang YG, Xia Y, Sun J. Imbalance of autophagy and apoptosis in intestinal 830 epithelium lacking the vitamin D receptor. FASEB J 2019:fj201900727R.

83155 Lu R, Wu S, Liu X, Xia Y, Zhang YG, Sun J. Chronic effects of a Salmonella type III 832 secretion effector protein AvrA in vivo. PLoS One 2010;5:e10505.

83356 Lu R, Voigt RM, Zhang Y, Kato I, Xia Y, Forsyth CB, et al. Alcohol Injury Damages 834 Intestinal Stem Cells. Alcoholism, clinical and experimental research 2017;41:727-34.

83557 Wu S, Xia Y, Liu X, Sun J. Vitamin D receptor deletion leads to reduced level of 836 IkappaBalpha protein through protein translation, protein-protein interaction, and 837 post-translational modification. Int J Biochem Cell Biol 2010;42:329-36.

$838 \quad 58 \quad$ Zhang Y-g, Xia Y, Sun J. A simple and sensitive method to detect vitamin D 839 receptor expression in various disease models using stool samples. Genes \& Diseases 8402020. 
Figure.1

A

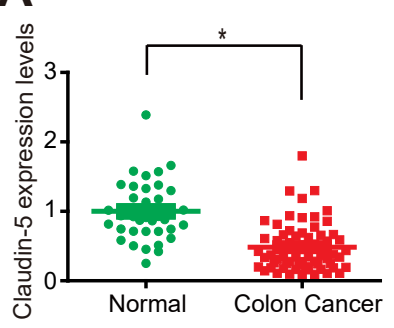

C

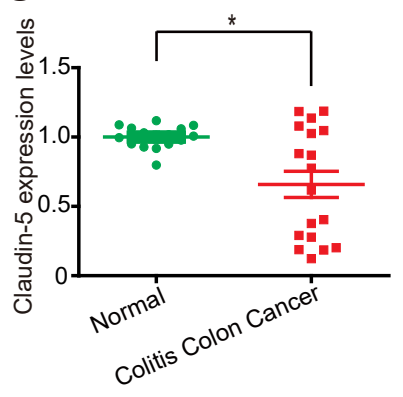

E Human Samples

Normal

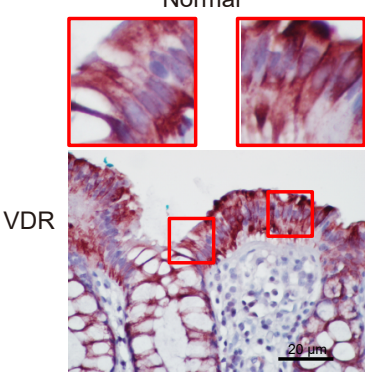

$\mathbf{F}$
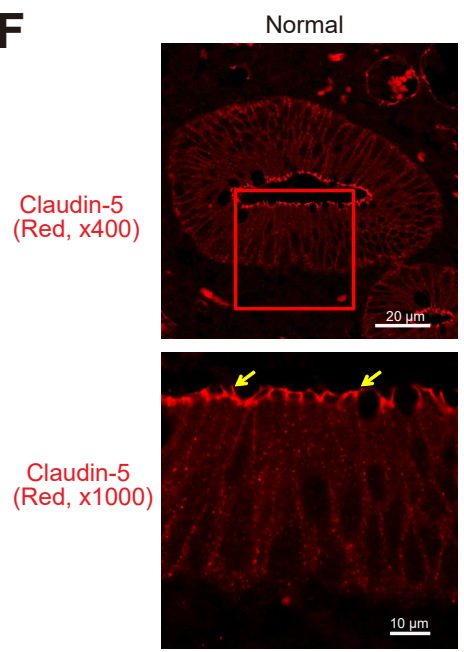

G

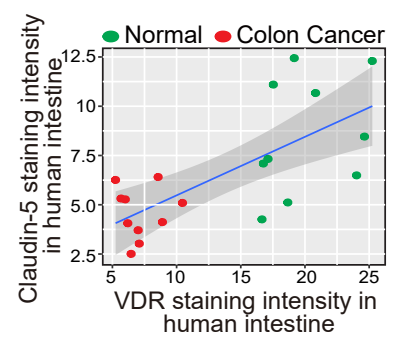

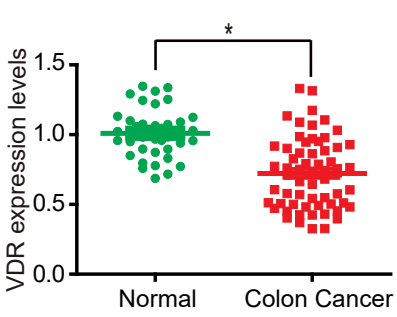

B

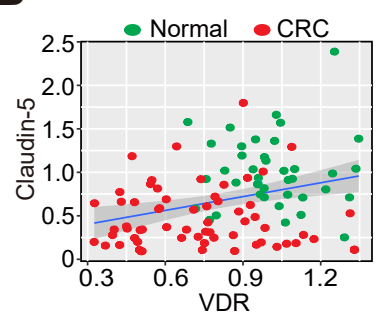

D
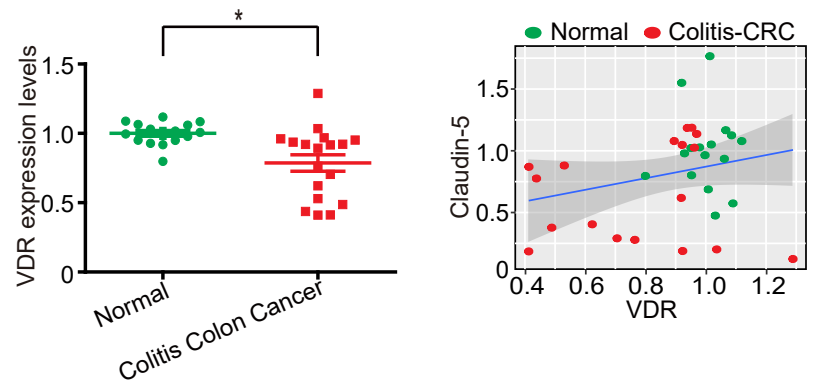

Colon Cancer
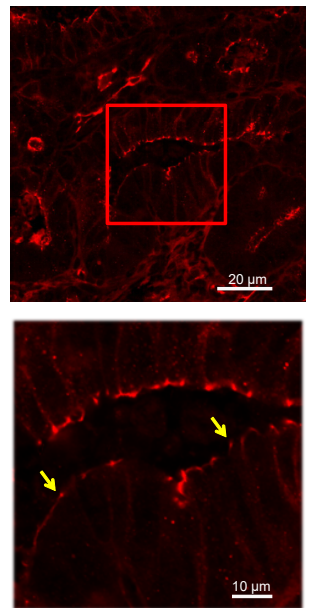

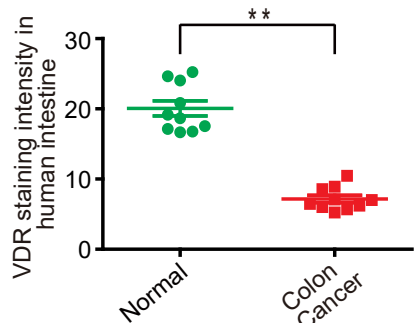

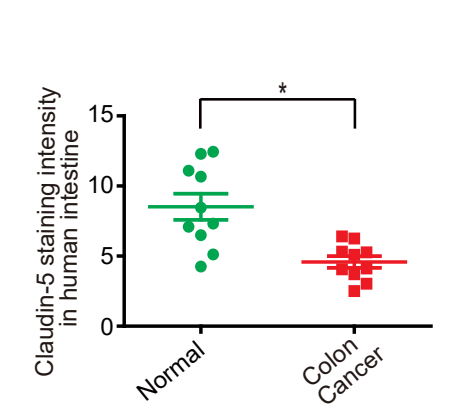

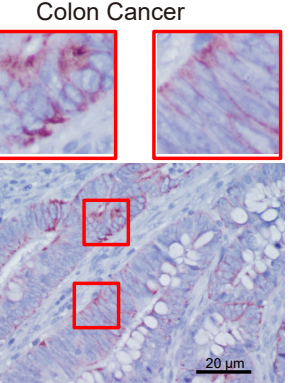


Figure.2

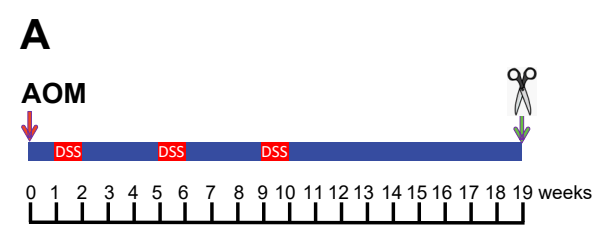

B

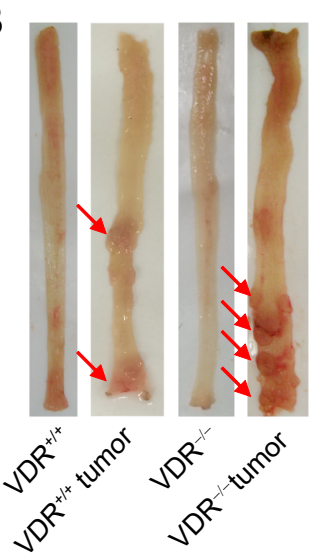

C

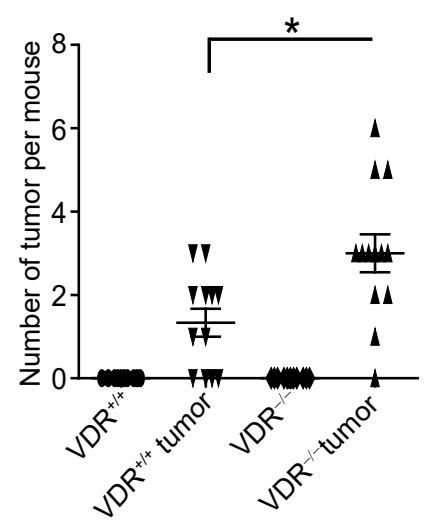

D

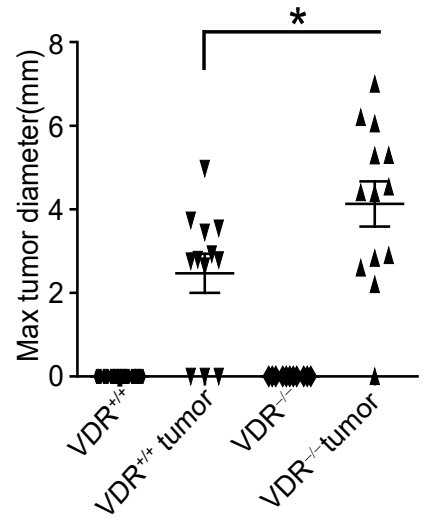

$\mathbf{E}$

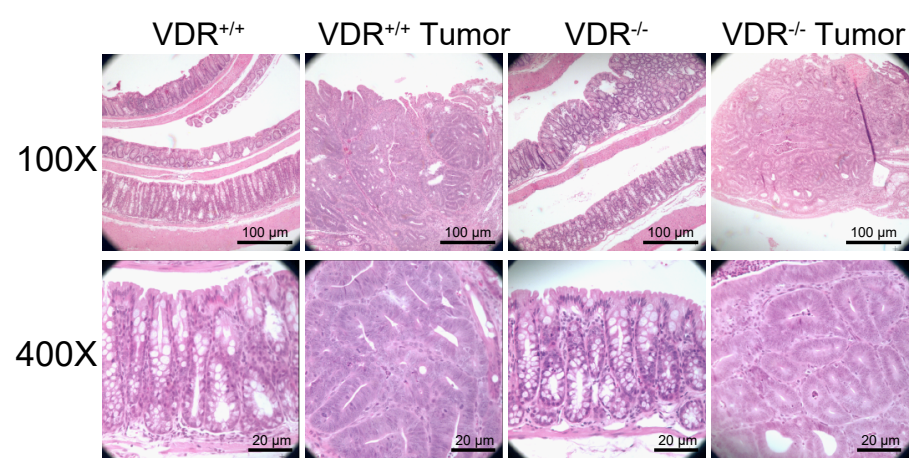

$\mathbf{F}$

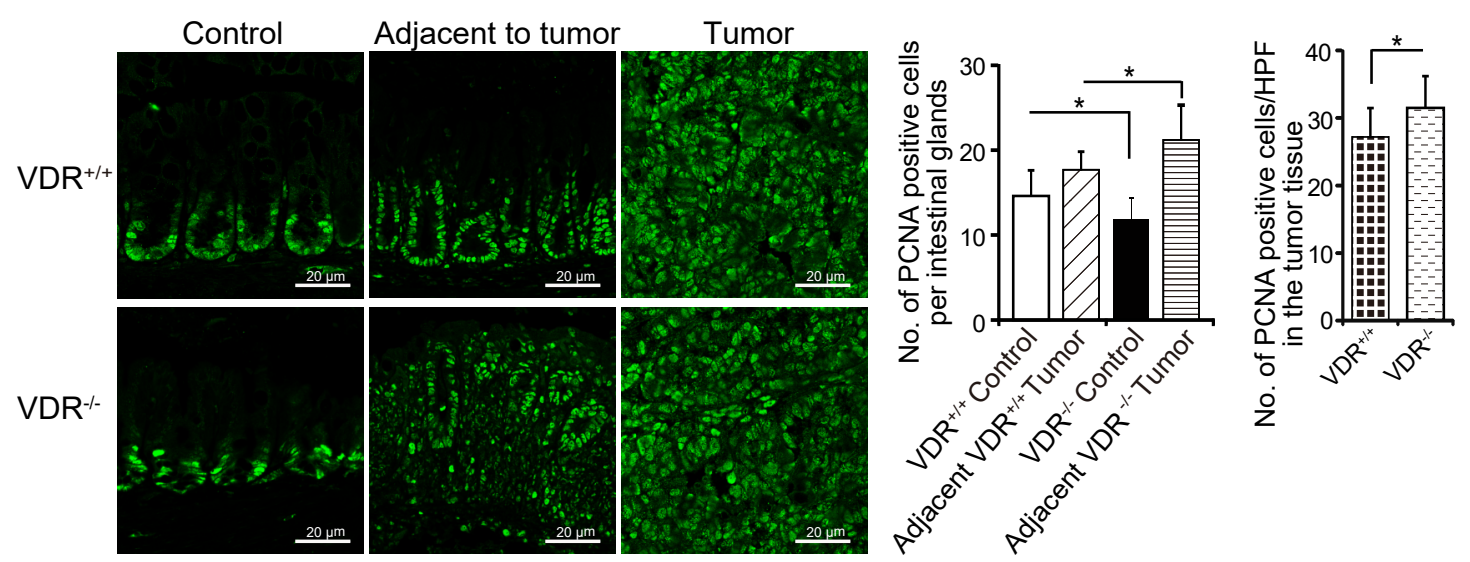

G
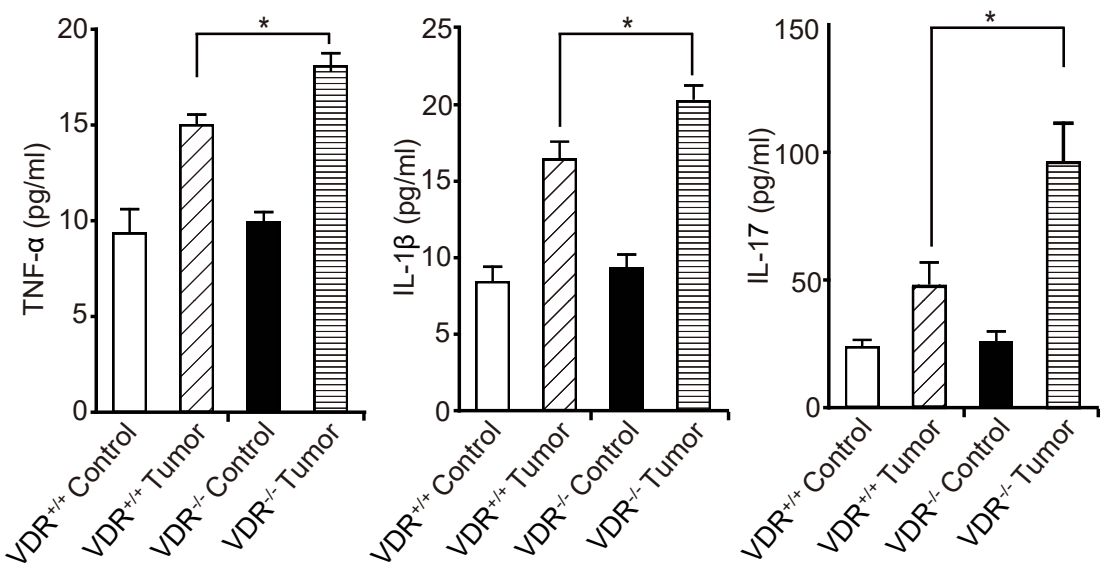
Figure. 3

A

C
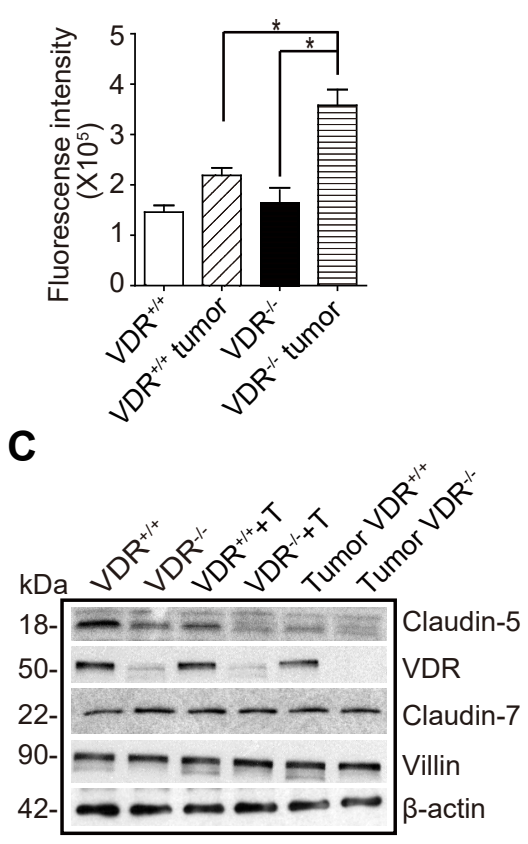

B
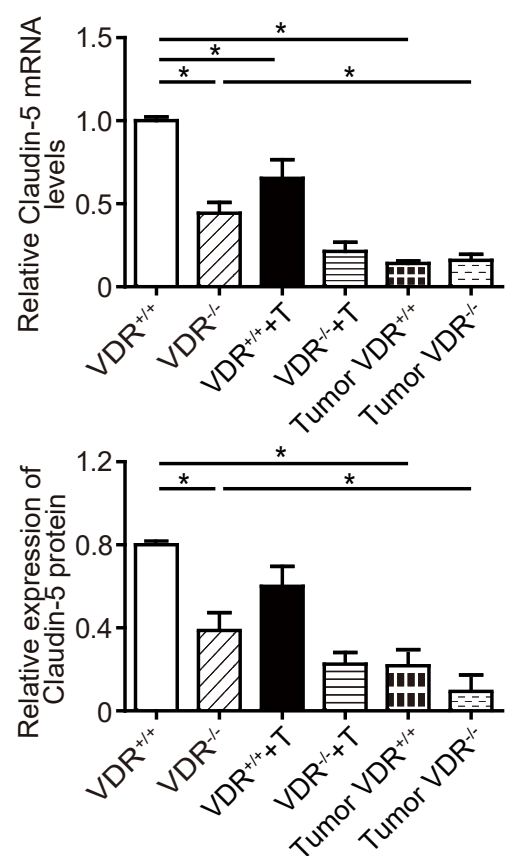

D

F

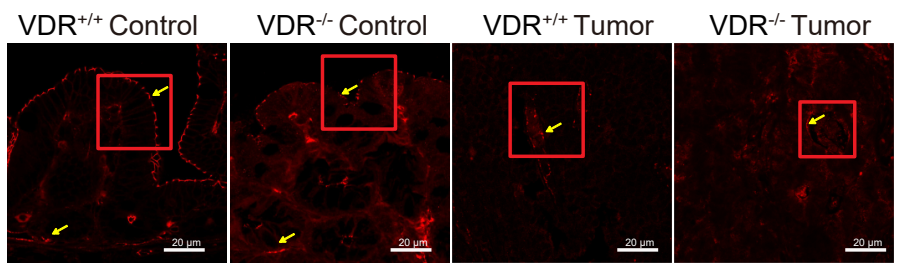

Claudin-5

(Red, x400)

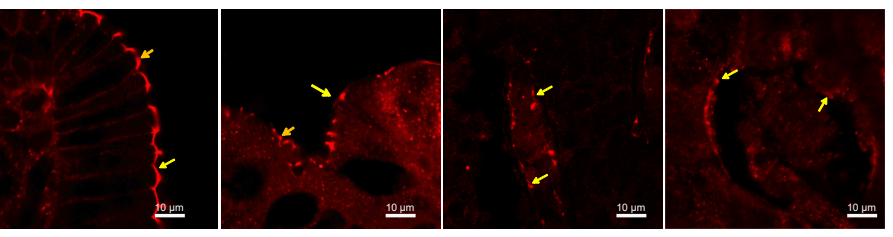

E

Claudin-5

(Red, x1200

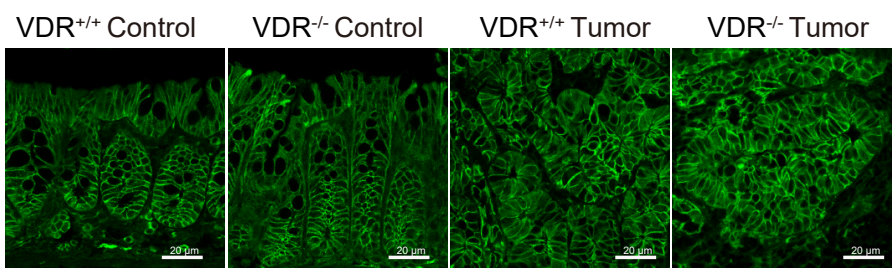

Claudin-7

(Green, x400

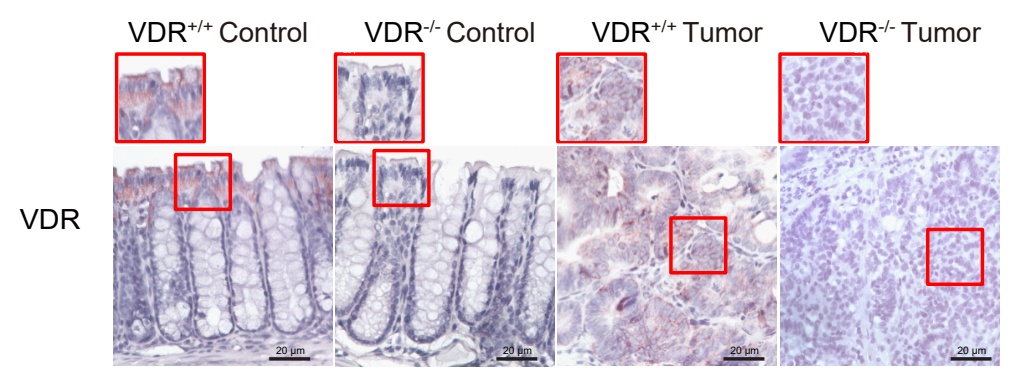

G

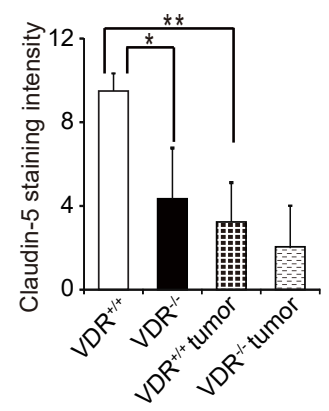

H

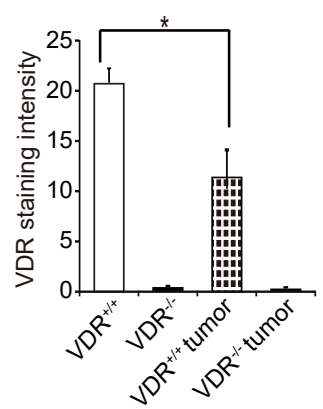

\section{Fecal samples}

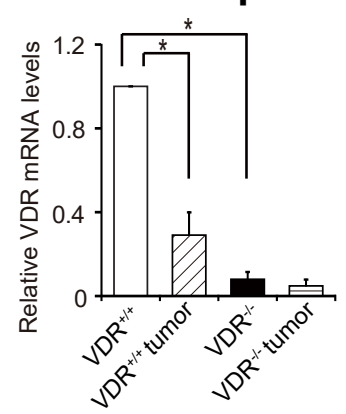


Figure. 4

A

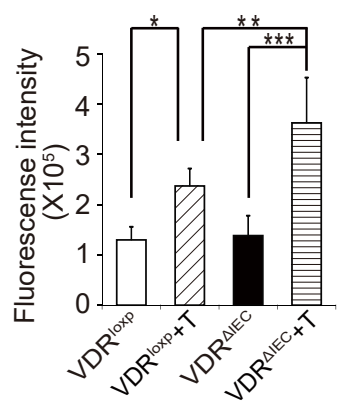

C

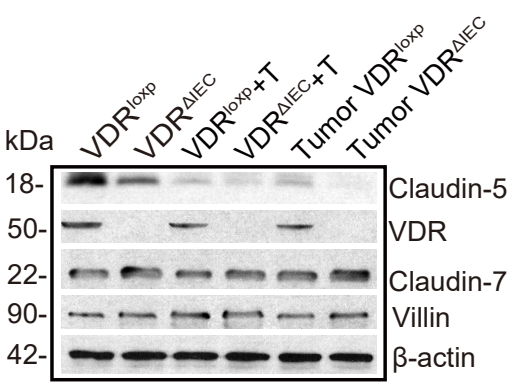

B
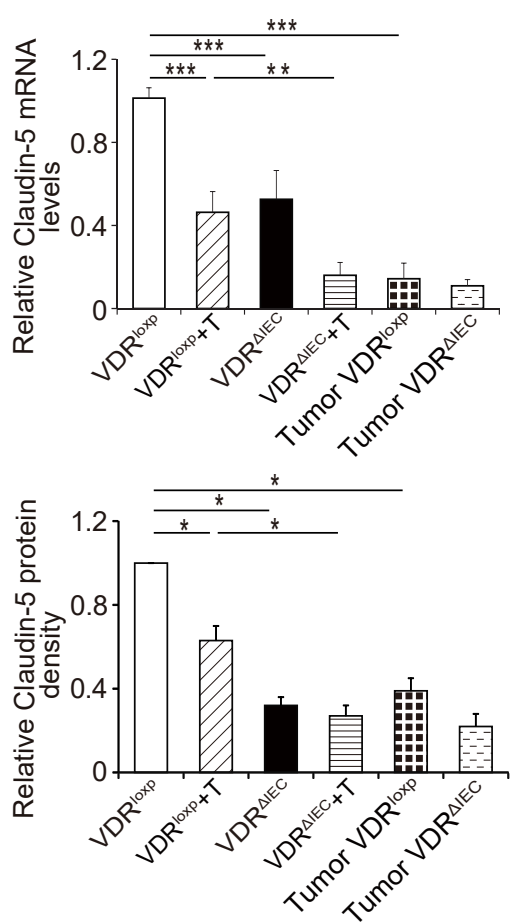

D VDR $^{\operatorname{loxp}}$ Control VDR ${ }^{\triangle I E C}$ Control VDR ${ }^{\operatorname{loxp}}$ Tumor VDR ${ }^{\triangle I E C}$ Tumor

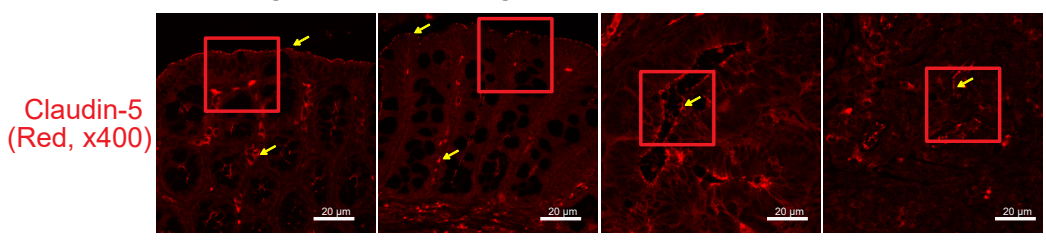

Claudin-5 (Red, x1200)
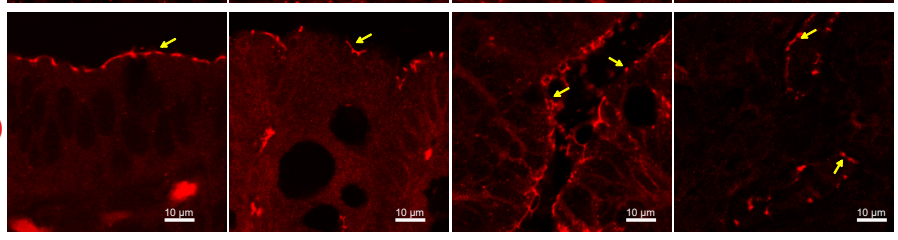

$\mathbf{E}$

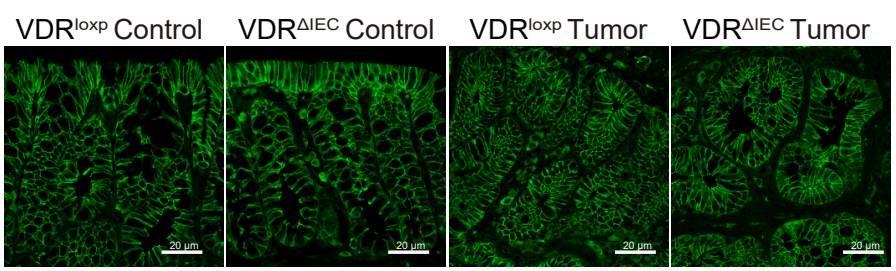

F

G Fecal samples
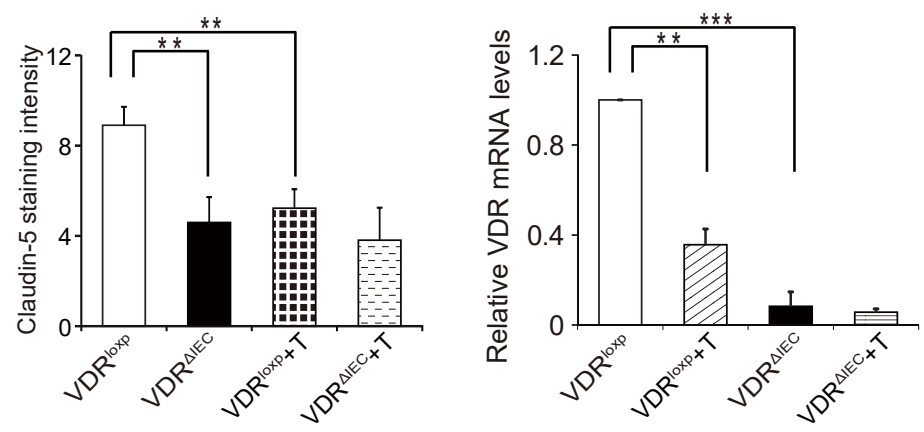
Figure. 5

A

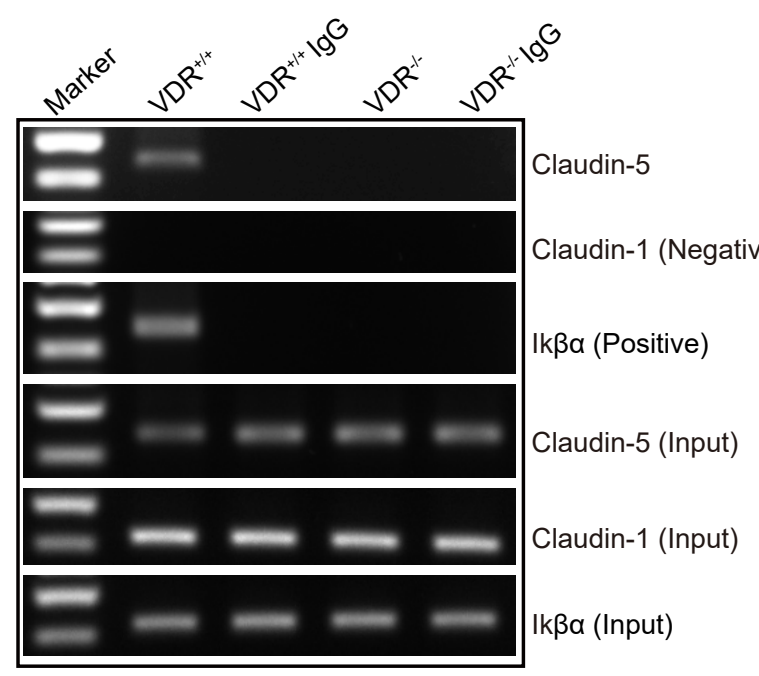

B VDRE in Claudin-5 promoter $\frac{\text { VDRE Site }}{-\frac{\text { AGTTTGGTTGTGGGCT- }}{\uparrow}}$ VDR $\lg G$

\section{SKC015}

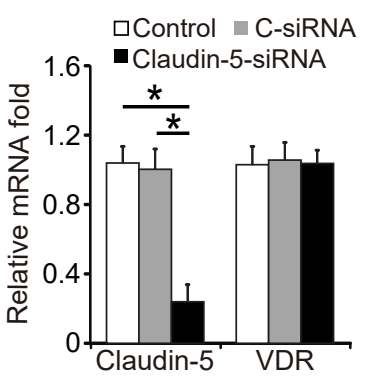

D
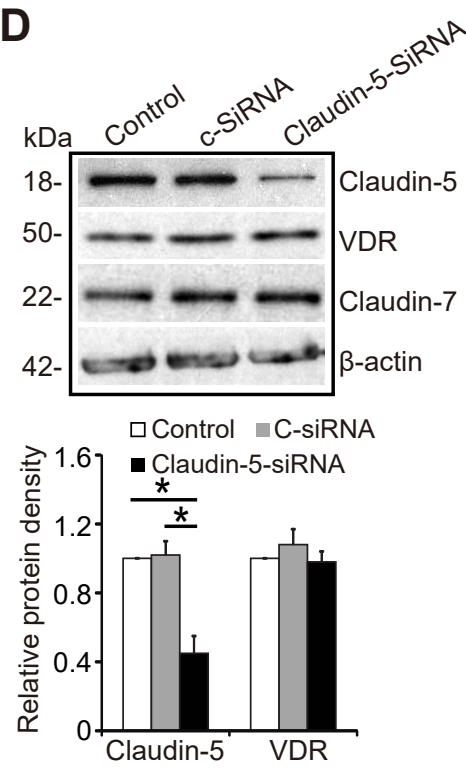
Figure. 6

\section{A SKC015}

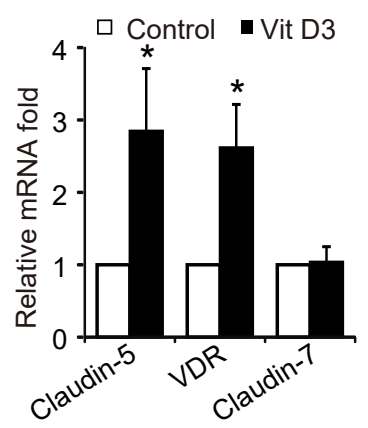

\section{Mice colon}

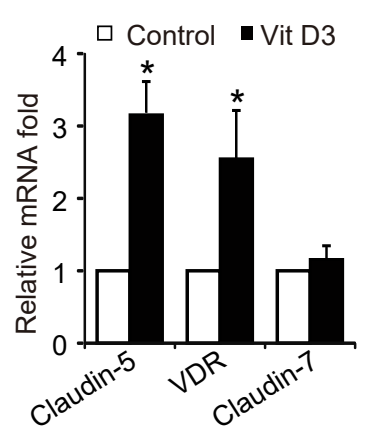

\section{E Human Colonoids}
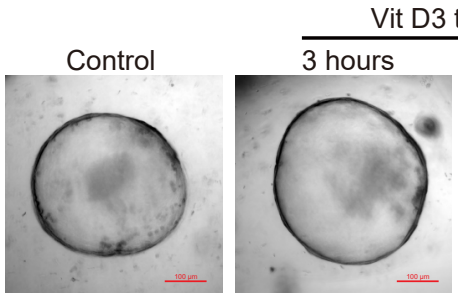

G

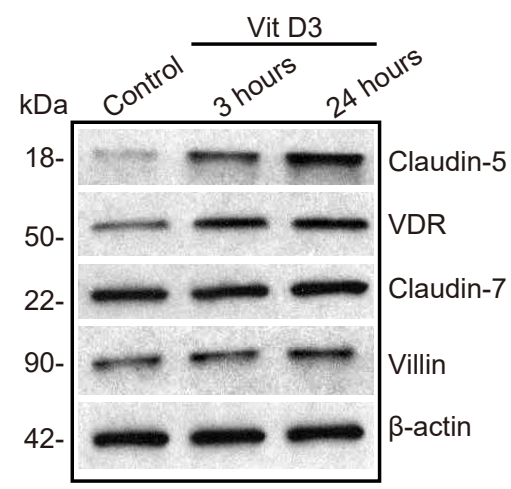

\section{B}

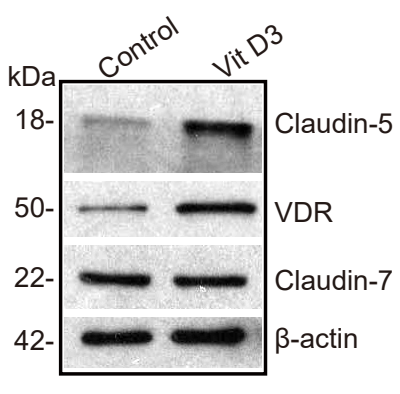

D
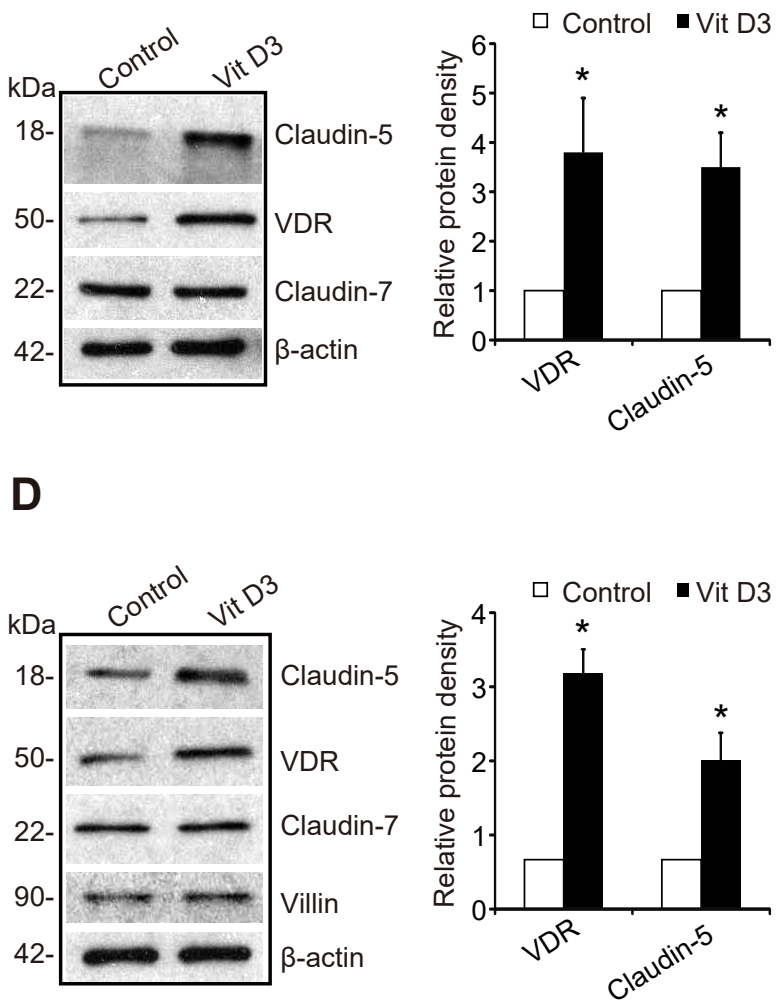

$\mathbf{F}$

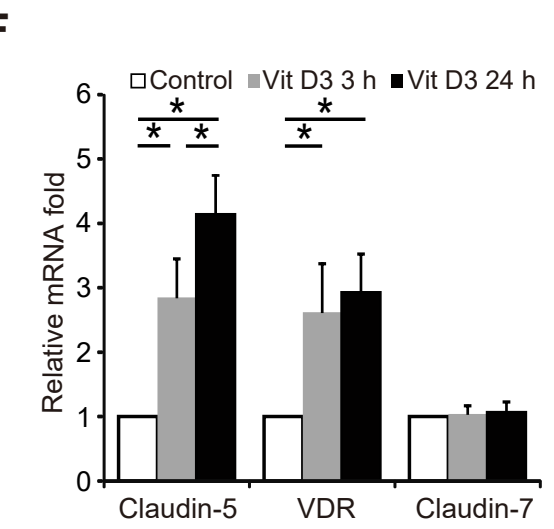

口Control $\square$ Vit D3 $3 \mathrm{~h}$

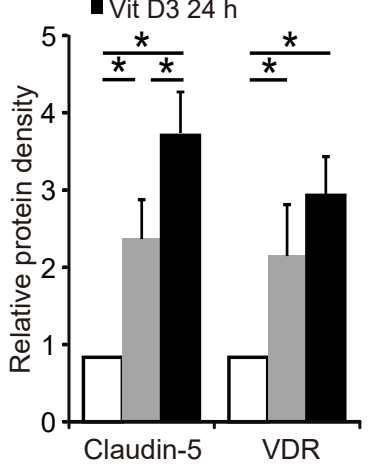


A
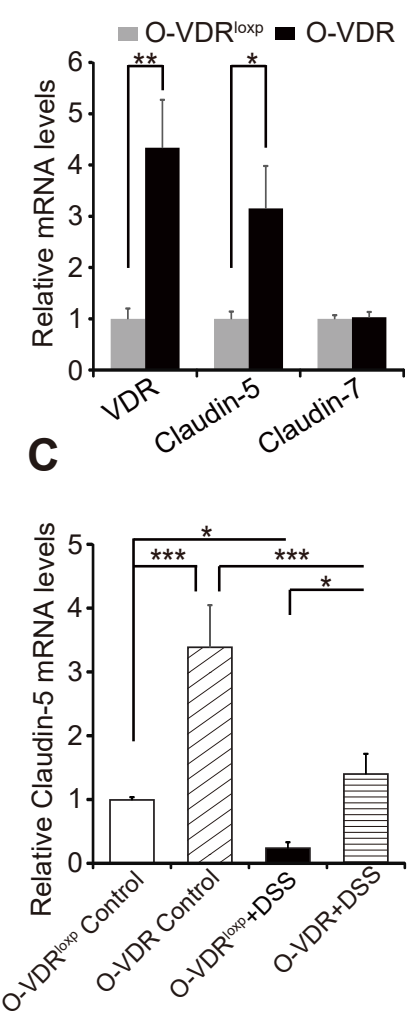

B
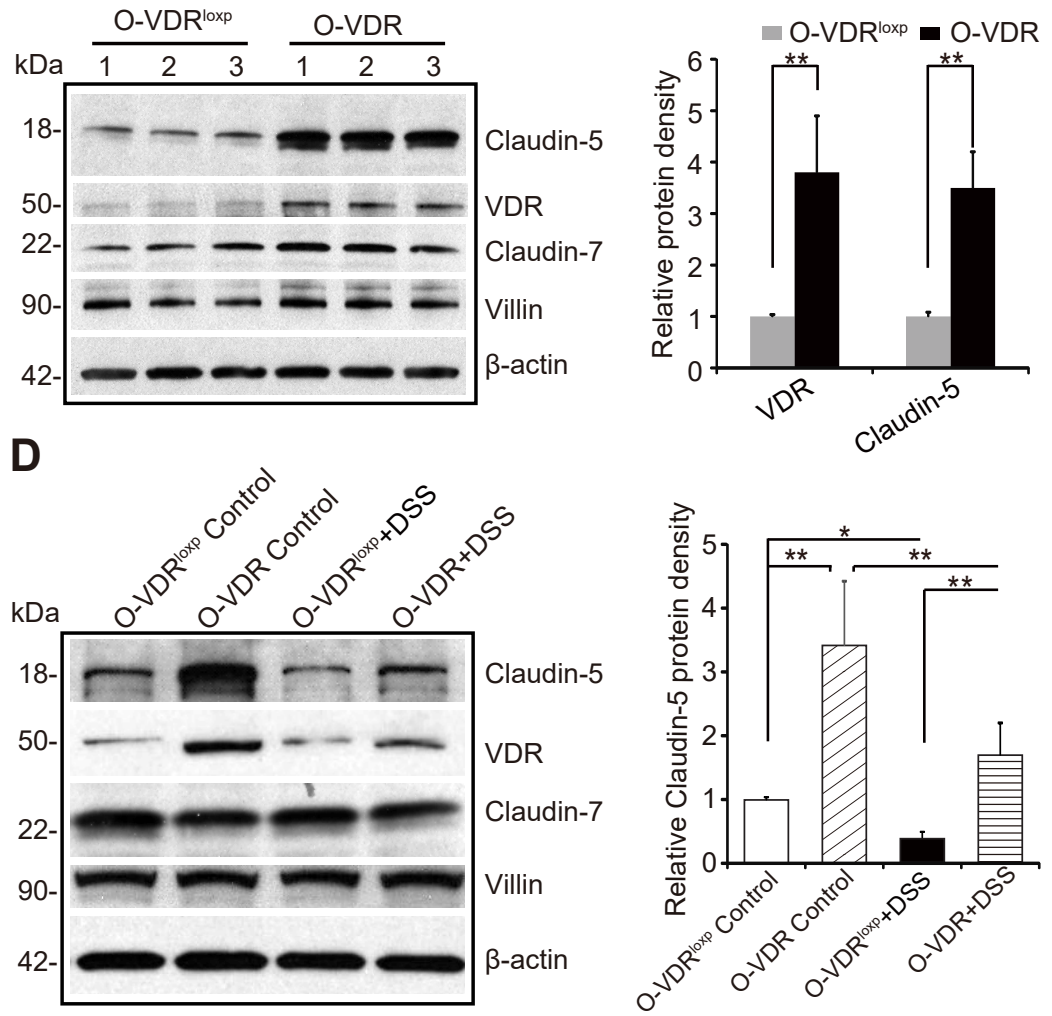

E

O-VDR ${ }^{\text {loxp }}$ Control
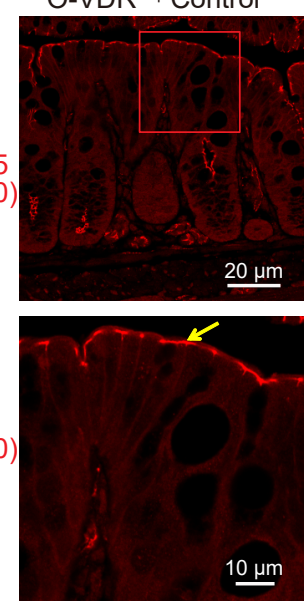

$\mathbf{F}$

Claudin-7 (Green, x400)

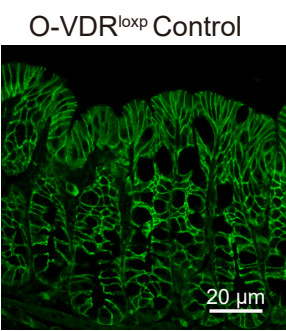

O-VDR Control
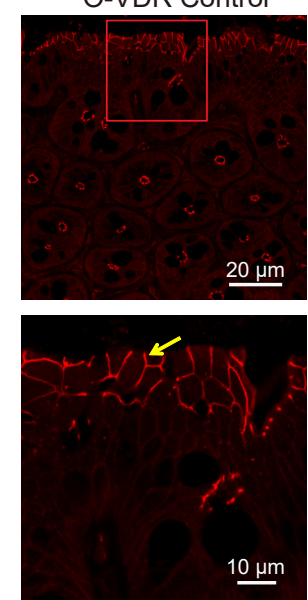

O-VDR Control

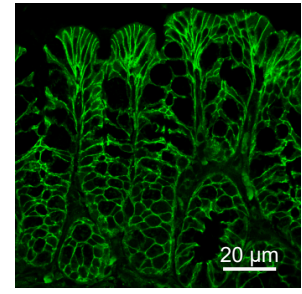

H Fecal samples

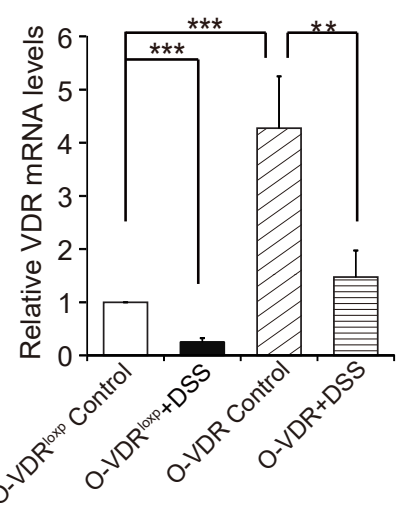

O-VDR ${ }^{\operatorname{loxp}}$ DSS
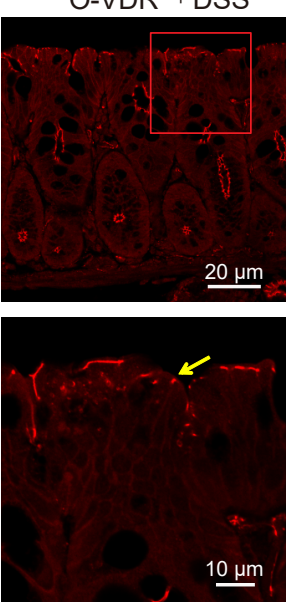

O-VDR ${ }^{\operatorname{loxp}} \mathrm{DSS}$

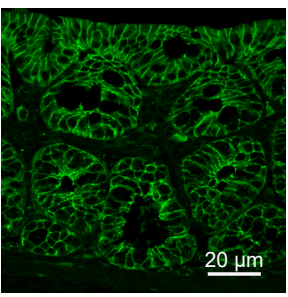

O-VDRDSS
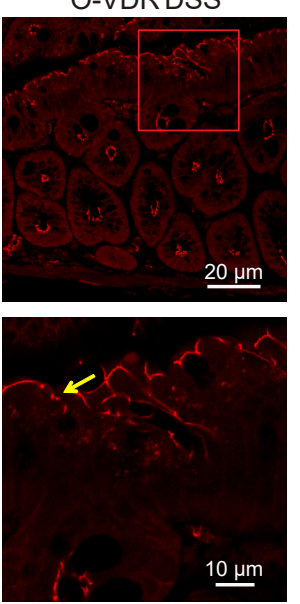

O-VDRDSS

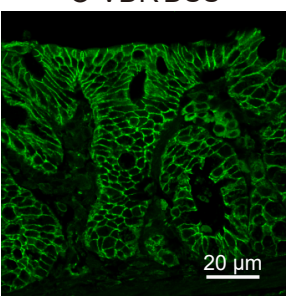

G

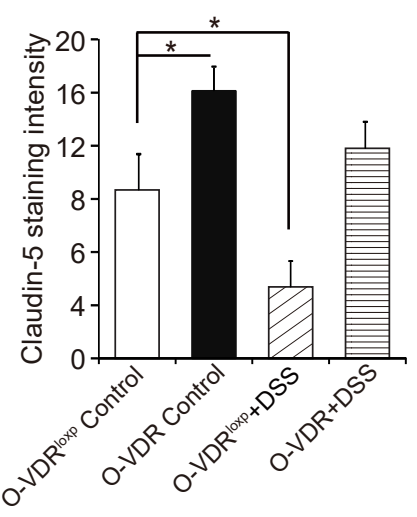

I Colon (RT-PCR)

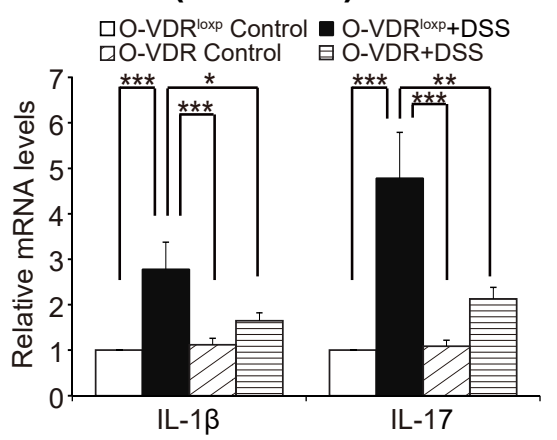


Fig. S1. VDR deficiency in intestinal epithelial cells of mice leads to the reduction of Claudin- 5 at both the mRNA and protein levels in vivo.

(A) Claudin-5 protein and (B) mRNA levels were significantly lower in $\mathrm{VDR}^{-/-}$mice compared to levels in the $\mathrm{VDR}^{+/+}$mice (data are expressed as mean $\pm \mathrm{SD} . \mathrm{n}=5$, student's t-test, $\left.{ }^{*} \mathrm{P}<0.05\right)$. (C) Location of Claudin- 5 protein in the colons of $\mathrm{VDR}^{+/+}$and $V_{D R}{ }^{-/}$mice. Images are from a single experiment and are representative of 5 mice per group. (D) Claudin-5 protein and (E) mRNA levels were significantly lower in VDR ${ }^{\Delta I E C}$ mice compared to levels in the $\operatorname{VDR}^{\text {loxp }}$ mice (data are expressed as mean $\pm S D . n=5$, student's t-test, $\left.{ }^{*} \mathrm{P}<0.05\right)$. (F) Claudin-5 protein and (G) mRNA were both decreased in $V_{D R}{ }^{--}$MEF cells (data are expressed as mean $\pm S D . n=3$, student's t-test, ${ }^{*} P<0.05$ ). (H) Location and quantification of Claudin-5 protein in $\mathrm{VDR}^{+/+}$and $\mathrm{VDR}^{-/-} \mathrm{MEF}$ cells. Images are from a single experiment performed in triplicate. (Data are expressed as mean $\pm S D . n=3$, one-way ANOVA test, $\left.{ }^{*} \mathrm{P}<0.05\right)$. 
A

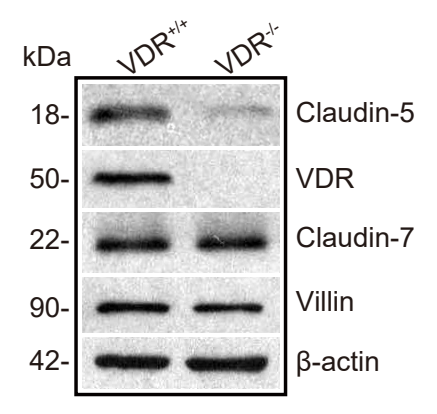

C

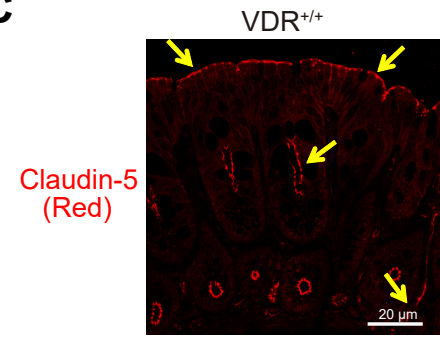

D

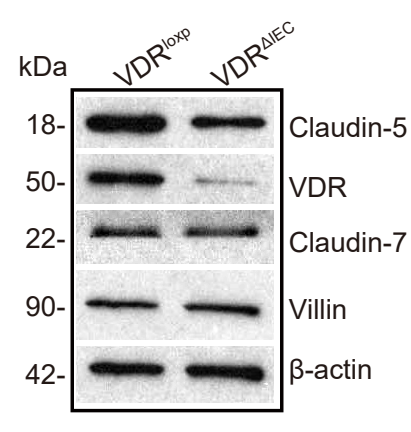

F
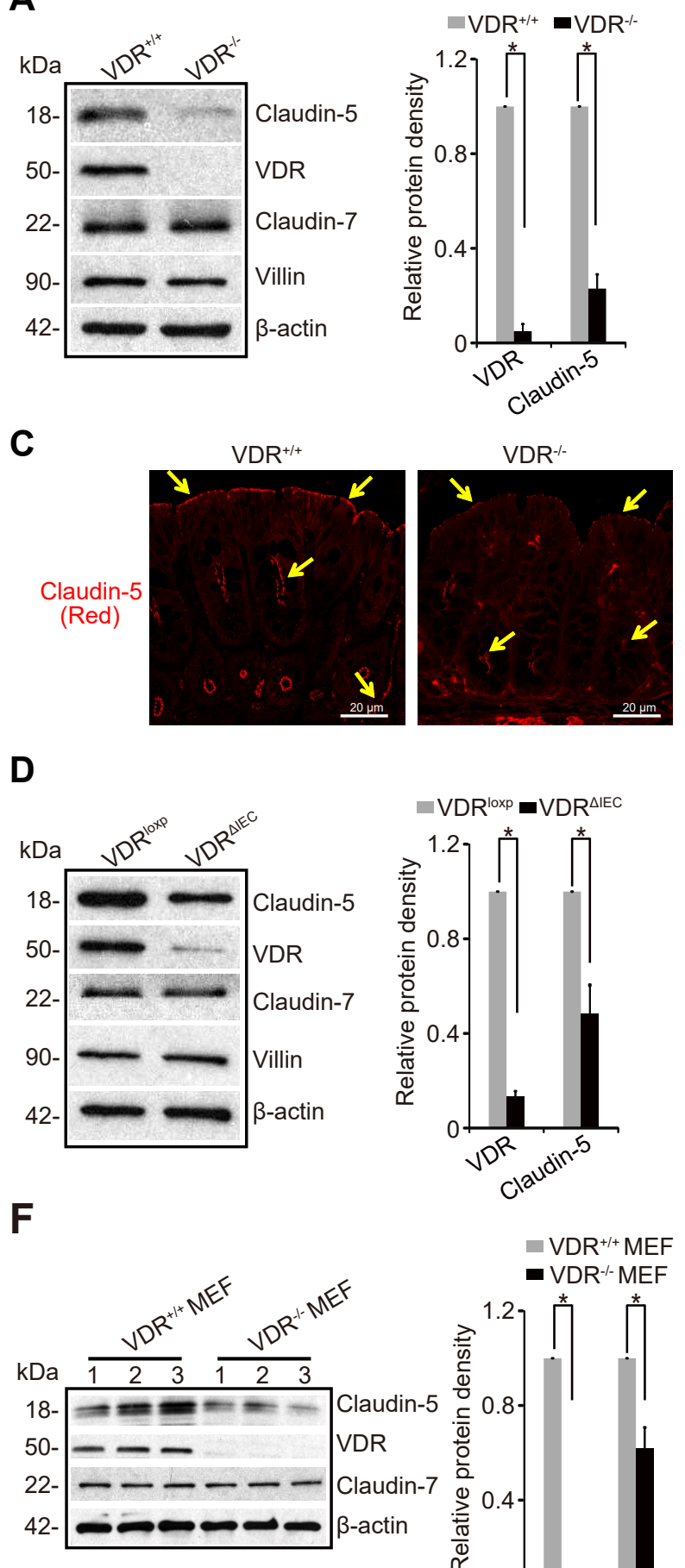

- $\mathrm{VDR}^{-/-} \mathrm{MEF}$

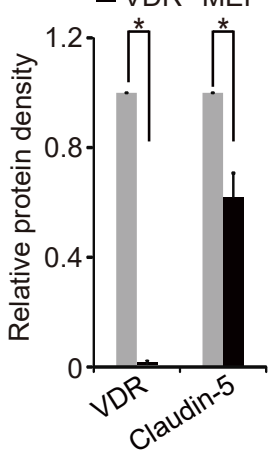

B
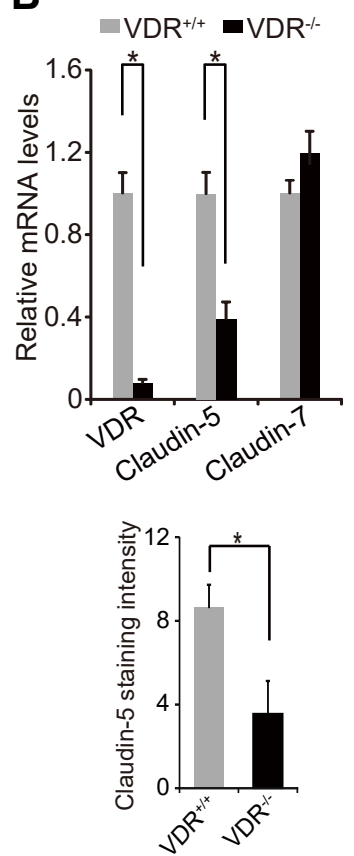

E

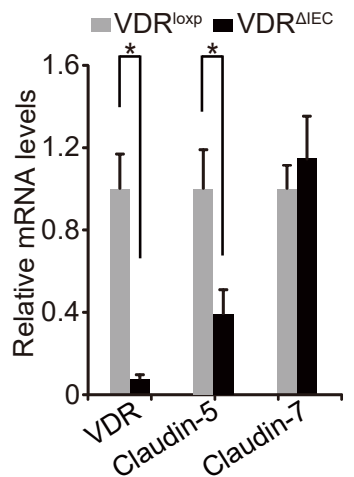

G

- $\mathrm{VDR}^{+/+} \mathrm{MEF}$

- $\mathrm{VDR}^{-1-} \mathrm{MEF}$

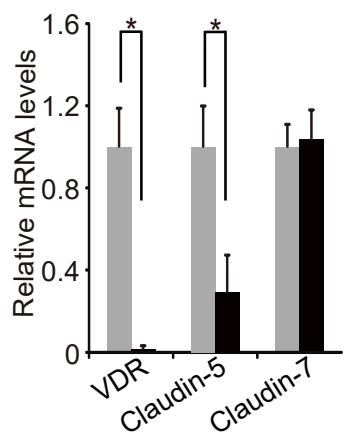

H

Claudin-5 (Green, x400)

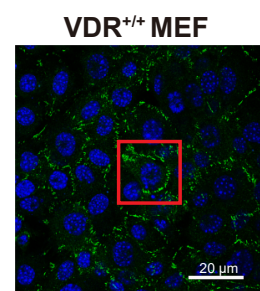

VDR $^{-\digamma}$ MEF

Claudin-5
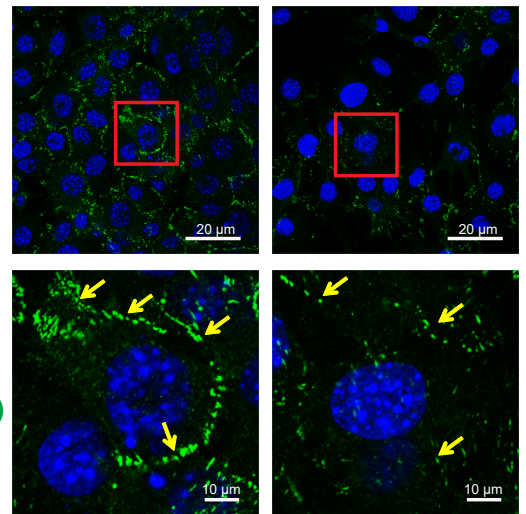

" $<$

$\swarrow$
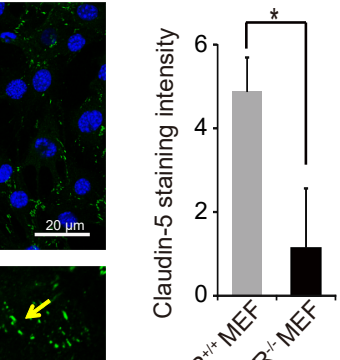

(Green, x1600)
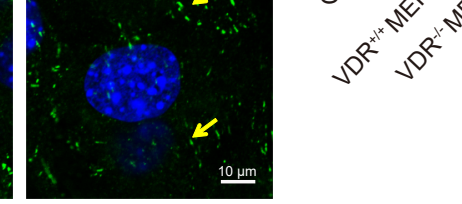